\title{
Saharan Heat Low Biases in CMIP5 Models 0
}

\author{
Ross D. Dixon, Anne Sophie Daloz, And Daniel J. Vimont \\ Department of Atmospheric and Oceanic Sciences, and Nelson Institute Center for Climatic Research, \\ University of Wisconsin-Madison, Madison, Wisconsin \\ Michela BiasutTi \\ Lamont-Doherty Earth Observatory, Columbia University, Palisades, New York
}

(Manuscript received 12 February 2016, in final form 18 November 2016)

\begin{abstract}
Representing the West African monsoon (WAM) is a major challenge in climate modeling because of the complex interaction between local and large-scale mechanisms. This study focuses on the representation of a key aspect of West African climate, namely the Saharan heat low (SHL), in 22 global climate models from phase 5 of the Coupled Model Intercomparison Project (CMIP5) multimodel dataset. Comparison of the CMIP5 simulations with reanalyses shows large biases in the strength and location of the mean SHL. CMIP5 models tend to develop weaker climatological heat lows than the reanalyses and place them too far southwest. Models that place the climatological heat low farther to the north produce more mean precipitation across the Sahel, while models that place the heat low farther to the east produce stronger African easterly wave (AEW) activity. These mean-state biases are seen in model ensembles with both coupled and fixed sea surface temperatures (SSTs). The importance of SSTs on West African climate variability is well documented, but this research suggests SSTs are secondary to atmospheric biases for understanding the climatological SHL bias. SHL biases are correlated across the models to local radiative terms, large-scale tropical precipitation, and large-scale pressure and wind across the Atlantic, suggesting that local mechanisms that control the SHL may be connected to climate model biases at a much larger scale.
\end{abstract}

\section{Background}

The Sahel region of West Africa, located between the dry Sahara Desert to the north and the moist savannah to the south, is characterized by a wet season, known as the West African monsoon (WAM), and a dry season with a period of sharp transition between them. The Sahel receives most of its annual rainfall between May and October, and it is this summer precipitation that provides those who live in the region with the water needed for agriculture and their wellbeing. Devastating droughts across the Sahel in the 1970s and 1980s raised interest in observing and modeling West African climate (Nicholson 2013). Projections of Sahel precipitation through the twenty-first

Supplemental information related to this paper is available at the Journals Online website: http://dx.doi.org/10.1175/JCLI-D-16-0134.s1.

Corresponding author e-mail: Ross D. Dixon, rddixon@wisc.edu century are inconsistent across different climate models, some even showing opposite trends (Biasutti et al. 2006, 2009; Monerie et al. 2012, 2013; Park et al. 2015). Understanding why climate models produce different behavior in this region is still an open question.

Several studies have emphasized the importance of sea surface temperature (SST) on the variability in Sahel rainfall at time scales from intraseasonal to interdecadal (Folland et al. 1986; Giannini et al. 2003; Haarsma et al. 2005; Held et al. 2005; Ndiaye et al. 2011; Giannini et al. 2013; Rodríguez-Fonseca et al. 2015). WAM variability and change are also forced from the north, through variation in a semistationary heat low (the West African heat low) that forms over the warm regions of West Africa (Biasutti et al. 2009; Evan et al. 2015).

The West African heat low is a region of low surface pressure that develops in the summer associated with seasonal high surface temperatures and insolation over West Africa. The position of the West African heat low has a strong seasonal variation: north-south owing to 

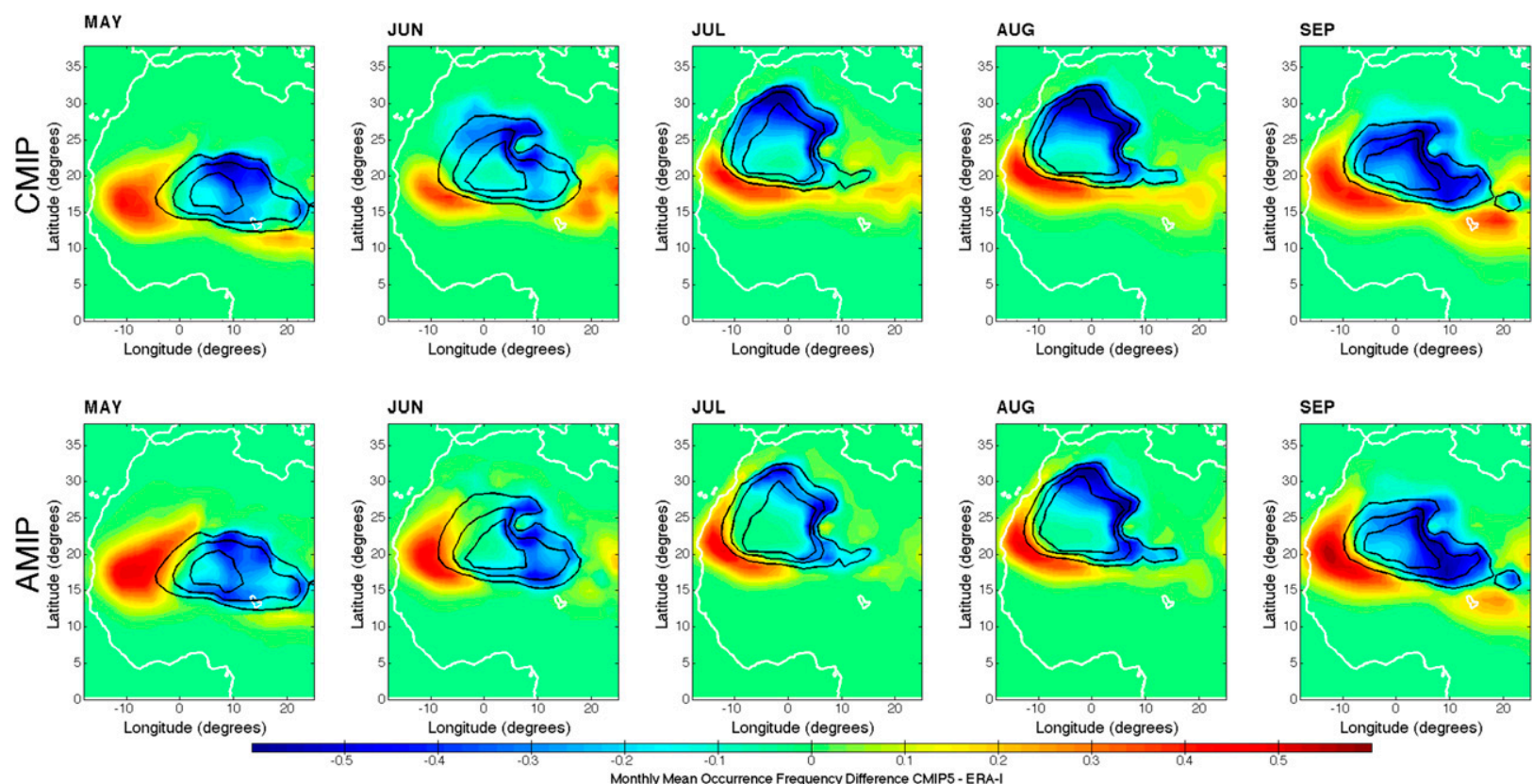

FIG. 1. (top) CMIP and (bottom) AMIP ensemble monthly mean bias color shading with the ERA-I monthly average heat low occurrence frequency (black contours with occurrence frequencies of 0.7, 0.8, and 0.9). These frequencies represent how often the detection algorithm locates the heat low in each grid box. The biases are computed by subtracting the model ensemble mean occurrence frequency from the reanalysis occurrence frequency.

the seasonal cycle of insolation and east-west owing to complicated orographic forcing (Lavaysse et al. 2009; Drobinski et al. 2005). The location of the low during May through September in the reanalysis can be seen in Fig. 1 in the thick black contours. During the boreal summer, the low deepens over the western Sahara as a result of extreme surface temperatures (Lavaysse et al. 2009) and is referred to as the Saharan heat low (SHL). In this paper we focus on the boreal summer and hence refer to the heat low as the SHL even during the transitional periods as it moves in and out of the Sahara.

The SHL plays an important role in the circulation over West Africa, where it is associated with the low-level cyclonic circulation that brings moisture into the Sahel region from the Atlantic Ocean and produces low-level convergence between the Sahara and Sahel regions. This moisture convergence helps drive the monsoon (Sultan and Janicot 2003; Sultan et al. 2003; Ramel et al. 2006; Hagos and Cook 2007). Above the low-level circulation, a midlevel anticyclonic wind flows into the temperaturegradient-driven African easterly jet (AEJ) around the southern boundary of the low. Within the AEJ, African easterly waves (AEWs) develop from instabilities associated with latent heat release and convection and are sustained by the energy they extract from the zonal jet (Hsieh and Cook 2008; Thorncroft and Blackburn 1999).

The SHL has been studied extensively in reanalyses. Lavaysse et al. (2009) developed a 35-yr climatology of the SHL using the ERA-40 reanalysis, detailed its seasonal migration and variability, and showed that its circulation was related to monsoon onset. Other studies revealed that variability in the SHL, on time scales ranging from synoptic to interannual, can affect the onset, temporal evolution, and strength of the WAM (Evan et al. 2015; Chauvin et al. 2010; Lavaysse et al. 2010a,b).

Processes that influence the SHL strength and location in the reanalyses include the import of temperature, moisture, and dust into the western Sahara. Midlatitude waves inject cool extratropical air into the Sahara, affecting the Saharan temperature and SHL strength (Vizy and Cook 2009; Chauvin et al. 2010; Lavaysse et al. 2010a; Roehrig et al. 2011). Atmospheric circulation patterns can bring dust (Lavaysse et al. 2011; Engelstaedter et al. 2015) and moisture (Evan et al. 2015) into the Saharan region, which can also alter the local radiative budget, warm or cool the surface, and lead to fluctuations in the SHL strength.

Understanding how the SHL is represented in climate models has been relatively unexplored. Model projections using phase 3 of the Coupled Model Intercomparison Project (CMIP3) showed that the trend in future Sahel rainfall is closely related to the intensity of the SHL (Biasutti et al. 2009); however, the spatial structure of the climatological model SHL was not investigated. Lavaysse et al. (2015) analyzed model representations of the daily variance in SHL on a variety of intraseasonal time scales to study how models produce 
the pulsations in the SHL connected with recent trends in West African climate. They found large discrepancies in the spatial and temporal evolution of the SHL between reanalyses and the model ensemble and showed that the climate models exhibited a wide range of interactions between the WAM and the SHL.

In this paper, we focus on the climatological strength and location of the SHL in CMIP5 models. We will show that climate models suffer from significant SHL biases, that these biases are connected with other features of West African climate, and that they are forced primarily by atmospheric or land mechanisms. The remainder of our paper is organized as follows. Section 2 outlines the reanalysis and GCM data used in the study, describes the detection method for locating the SHL, and describes how indices were generated for several key features of West African climate. Section 3 identifies the SHL bias in CMIP5 models and details the relationships between the indices describing the SHL bias and West African climate. In section 4, we show how the indices are related to atmospheric structures on several different spatial scales. Section 5 discusses our results and proposes a few hypotheses on the origin of the SHL biases. Our conclusions can be found in section 6 .

\section{Models and methods}

Here we describe the model data and reanalysis products used in this study and how they are used to quantify the SHL location and strength.

\section{a. Reanalyses and CMIP5 models}

We know that the reanalyses are not ideal, as they are mixtures of sparse, in situ observations and imperfect numerical simulations; however, they are the best option to establish the climatology of this region. This study uses ERA-Interim (ERA-I) (Dee et al. 2011), MERRA (Rienecker et al. 2011), and JRA-55 (Kobayashi et al. 2015) because of their ability to reproduce climatological WAM precipitation (Vellinga et al. 2013). ERA-I and MERRA are also consistent with the directly observed Saharan surface temperature trends between 1979 and 2012 (Cook and Vizy 2015). This study uses 30 years of reanalysis output from the period 1979-2008. We include CFSR (Saha et al. 2010) in the supplemental material (Figs. S2-S4) but choose not to discuss it further because of its documented biases in regional rainfall (Lorenz and Kunstmann 2012; Janiga and Thorncroft 2013; Roberts et al. 2015).

We compare 22 GCMs with the reanalyses to determine how different models represent the SHL. The 22 GCMs come from the World Climate Research Programme's phase 5 of the Coupled Model
Intercomparison Project (CMIP5) multimodel dataset (Taylor et al. 2012). Table 1 lists the models included in this study. For each model, two sets of historical experiments were analyzed. Coupled runs are forced by observed atmospheric composition, solar irradiance fluctuations, and land-use changes and allow an interactive ocean to respond to the forcing. The output from these simulations will be referred to as the CMIP ensemble. The other type of experiment retains the forcings found in the CMIP simulations but fixes the SSTs to observed values, removing the oceanic response to atmospheric forcing. This set of experiments will be referred to as the AMIP ensemble. We chose to look at the AMIP ensemble in addition to the CMIP ensemble because the AMIP ensemble removes the variability associated with the different SST biases. SST variability has been shown to be strongly connected to variability in Sahel rainfall. We use 27 years of monthly averaged CMIP and AMIP data from the period 1979-2005. All models and reanalyses were linearly interpolated to a common $1.25^{\circ} \times 1.25^{\circ}$ grid for analysis.

\section{b. Heat low detection method}

We determine the strength and location of the heat low in both the reanalyses and the models using the low-level atmospheric thickness (LLAT) defined by Lavaysse et al. (2009) as the difference between the geopotential heights at 700 and $925 \mathrm{mb}(1 \mathrm{mb}=1 \mathrm{hPa})$. This field is computed for the West African region (0$40^{\circ} \mathrm{N}, 20^{\circ} \mathrm{W}-30^{\circ} \mathrm{E}$ ) each month, and values that exceed a detection threshold are deemed to be within the heat low. We define the relative detection threshold to be the $90 \%$ level of each month's cumulative probability distribution function of LLAT over the region.

The main methodological difference between this study and the study of Lavaysse et al. (2009) is that we use monthly data instead of daily 0600 UTC data to define the heat low, but a comparison of these two methods using the ERA-40 and ERA-I showed that this definition of the SHL is robust for the scope of our study. During the summer months when the heat low is located over the Sahara (JJA), the monthly LLAT methodology slightly overestimates occurrence frequencies in the center of the heat low region and slightly underestimates them around the edge. In boreal winter (DJF) the heat low moves southeastward to central Africa. During this time period, using monthly LLAT values overestimates the heat low occurrence on the coast of Cameroon, owing to the importance of boundary layer processes and the diurnal cycle. These biases (not shown) do not affect our ability to use monthly values to define the center of the heat low during April through October. Values of the detection 
TABLE 1. Name and description of CMIP5 models used in this study. (Acronym expansions are available online at http://www.ametsoc. org/PubsAcronymList.)

\begin{tabular}{|c|c|c|c|c|}
\hline Model name & Institution & Atm resolution (lat $\times$ lon) & Vertical levels & Model reference \\
\hline ACCESS1.0 & CSIRO-BoM & $1.25^{\circ} \times 1.875^{\circ}$ & 38 & Bi et al. (2013) \\
\hline ACCESS1.3 & CSIRO-BoM & $1.25^{\circ} \times 1.875^{\circ}$ & 38 & Bi et al. (2013) \\
\hline BCC_CSM1.1(m) & $\mathrm{BCC}$ & $1.12^{\circ} \times 1.12^{\circ}$ & 26 & Wu et al. (2014) \\
\hline BCC_CSM1.1 & $\mathrm{BCC}$ & $2.8^{\circ} \times 2.8^{\circ}$ & 26 & Wu et al. (2014) \\
\hline BNU-ESM & $\begin{array}{l}\text { College of Global Change and } \\
\text { Earth System Science (GCESS) }\end{array}$ & $2.8^{\circ} \times 2.8^{\circ}$ & 26 & Ji et al. (2014) \\
\hline CCSM4 & NCAR & $1.0^{\circ} \times 1.25^{\circ}$ & 26 & Gent et al. (2011) \\
\hline CESM1(CAM5) & NSF-DOE-NCAR & $1.0^{\circ} \times 1.25^{\circ}$ & 26 & Neale et al. (2012) \\
\hline CMCC-CM & $\mathrm{CMCC}$ & $0.75^{\circ} \times 0.75^{\circ}$ & 31 & Scoccimarro et al. (2011) \\
\hline CNRM-CM5 & $\mathrm{CMCC}$ & $1.4^{\circ} \times 1.4^{\circ}$ & 31 & Voldoire et al. (2013) \\
\hline CSIRO Mk3.6.0 & CSIRO-QCCCE & $1.875^{\circ} \times 1.875^{\circ}$ & 18 & Jeffrey et al. (2013) \\
\hline CanESM2 & $\mathrm{CCCma}$ & $2.8^{\circ} \times 2.8^{\circ}$ & 35 & Arora et al. (2011) \\
\hline FGOALS-g2 & $\begin{array}{l}\text { LASG-Center for Earth } \\
\text { System Science (CESS) }\end{array}$ & $2.8^{\circ} \times 2.8^{\circ}$ & 26 & Li et al. (2013) \\
\hline GFDL CM3 & NOAA/GFDL & $2.0^{\circ} \times 2.5^{\circ}$ & 48 & Donner et al. (2011) \\
\hline GISS-E2-R & NASA GISS & $2.0^{\circ} \times 2.5^{\circ}$ & 40 & Kim et al. (2012) \\
\hline HadGEM2-AO & Met Office Hadley Centre (MOHC) & $1.25^{\circ} \times 1.8^{\circ}$ & 38 & Jones et al. (2011) \\
\hline INM-CM4.0 & $\begin{array}{l}\text { Institute of Numerical } \\
\text { Mathematics (INM) }\end{array}$ & $1.5^{\circ} \times 2.0^{\circ}$ & 21 & Volodin et al. (2010) \\
\hline IPSL-CM5A-LR & IPSL & $1.8^{\circ} \times 3.75^{\circ}$ & 39 & Dufresne et al. (2013) \\
\hline IPSL-CM5B-LR & IPSL & $1.25^{\circ} \times 2.5^{\circ}$ & 39 & Dufresne et al. (2013) \\
\hline MIROC5 & MIROC & $1.4^{\circ} \times 1.4^{\circ}$ & 40 & Watanabe et al. (2010) \\
\hline MPI-ESM-LR & MPI & $1.9^{\circ} \times 1.9^{\circ}$ & 47 & Stevens et al. (2013) \\
\hline MRI-CGCM3 & MRI & $1.1^{\circ} \times 1.1^{\circ}$ & 48 & Yukimoto et al. (2012) \\
\hline NorESM1-M & Norwegian Climate Centre (NCC) & $1.9^{\circ} \times 2.5^{\circ}$ & 26 & Bentsen et al. (2013) \\
\hline
\end{tabular}

threshold, representing the heat low strength, are consistent using both methods throughout the entire year.

Applying this heat low detection method to ERA-I, MERRA, JRA-55, and each of the 22 CMIP and AMIP models allows us to evaluate the ability of climate models to represent the climatological SHL. The location of the SHL in the ERA-I is shown in Fig. 1 (open black contours with occurrence frequencies of $0.7,0.8$, and 0.9 ) for the months of May through September. MERRA and JRA-55 present similar spatial structures, so they are not shown. All the reanalyses show the SHL moving from the Sahel region into the Sahara, where it deepens through July and August, before following the solar forcing back to the south at the end of the boreal summer.

\section{c. Indices describing the West African mean state}

\section{1) LLAT THRESHOLD INDEX}

The LLAT detection method was applied for each month and model in the 27-yr CMIP and AMIP ensembles. For each model, the monthly values of the detection threshold were averaged together, forming an index describing the climatological heat low strength. The monthly mean detection threshold for each model is shown in Fig. 2 for the months of April through October. Also shown in Fig. 2 is the ERA-I (thick black line), MERRA (thick blue line), and JRA-55 (thick green line) detection threshold computed in the same manner. Each thin line represents the climatological SHL strength (the LLAT detection threshold) for a single model from the ensemble. The detection threshold is highest in the summer months (JJA), when the SHL is fully developed over the Sahara. This index for heat low strength will be referred to as LLAT TH.

\section{2) SAHARAN GEOPOTENTIAL PERTURBATION}

Another way to identify the strength of the SHL is to compare low-level geopotential heights across the Saharan region to the heights at the same level over the entire tropics. Following Biasutti et al. (2009), the 925-mb geopotential averaged over the Sahara $\left(20^{\circ}-30^{\circ} \mathrm{N}, 10^{\circ} \mathrm{W}-\right.$ $\left.35^{\circ} \mathrm{E}\right)$ is subtracted from the average $925-\mathrm{mb}$ geopotential across the entire tropics $\left(20^{\circ} \mathrm{S}-20^{\circ} \mathrm{N}\right)$ for each model and month, to give a climatological index of the regional monsoon circulation. At low levels and during summer months, when the heat low is located over the Sahara, it also describes the strength of the SHL. This geopotential perturbation index (ZGP; not shown) is computed to ensure consistency with earlier studies.

\section{3) LLAT NORTH-SOUTH AND EAST-WEST INDEX}

To generate indices that describe the location of the SHL, the LLAT method is used to generate spatial maps 

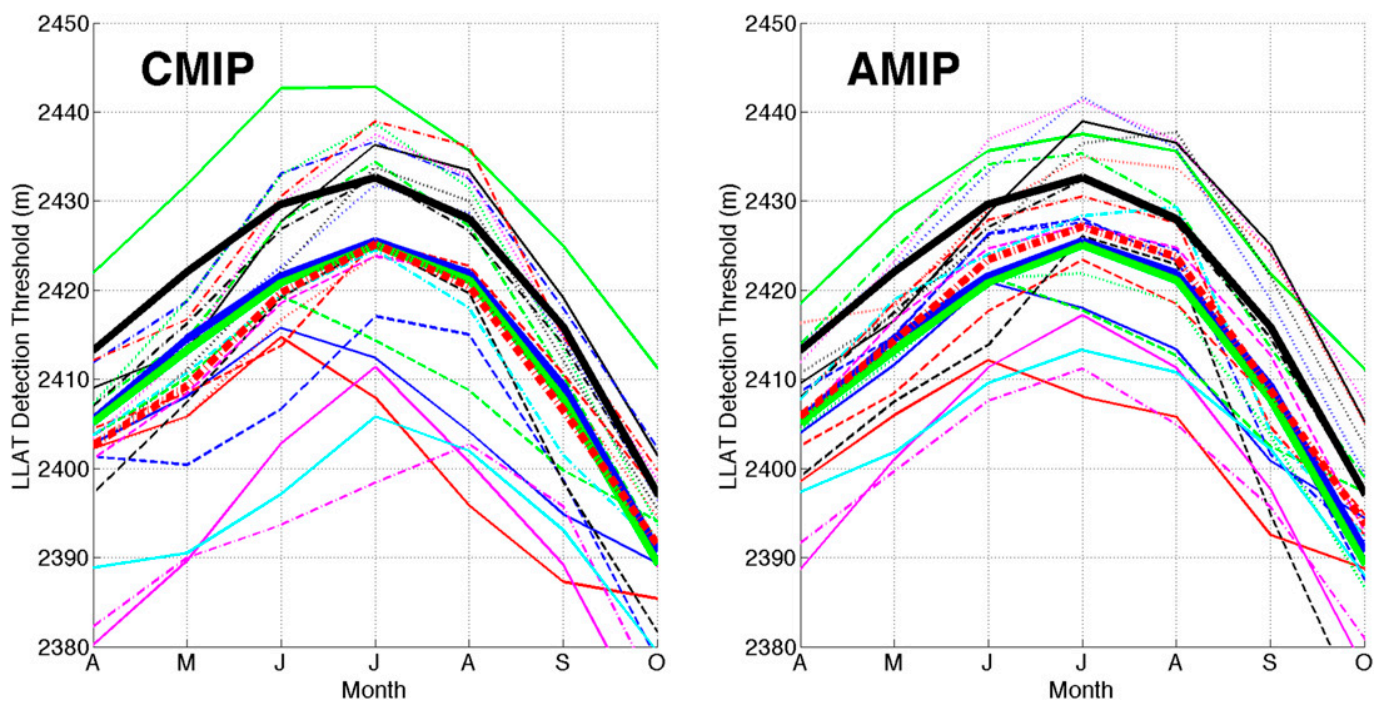

FIG. 2. (left) CMIP and (right) AMIP LLAT detection threshold values (m) for April through October. Each thin line represents a model from the ensemble (indicated in Fig. 4). The ERA-I (thick black line), MERRA (thick blue line), JRA-55 (thick green line), and ensemble average (thick dashed red line) LLAT detection thresholds are also shown for comparison.

similar to the ERA-I occurrence frequency shown in the black contours in Fig. 1. We use the 27-30 years of LLAT fields to form a climatology of the SHL occurrence for each model and reanalysis. From this climatology, the center of the SHL is determined using an algorithm that finds the region of highest occurrence frequency (greater than 0.7 within $0^{\circ}-40^{\circ} \mathrm{N}$ and $20^{\circ} \mathrm{W}-$ $15^{\circ} \mathrm{E}$ ) and averages those latitudes and longitudes to a single coordinate pair. These indices represent the climatological center of the SHL for each calendar month and each model. Several thresholds and methods were tested using visual inspection in order to choose the method that consistently placed the indices at the center of the SHL. The indices for the latitudinal position of the SHL (LLAT NS), are shown in Fig. 3. The indices for the ERA-I (thick black line), MERRA (thick blue line), and
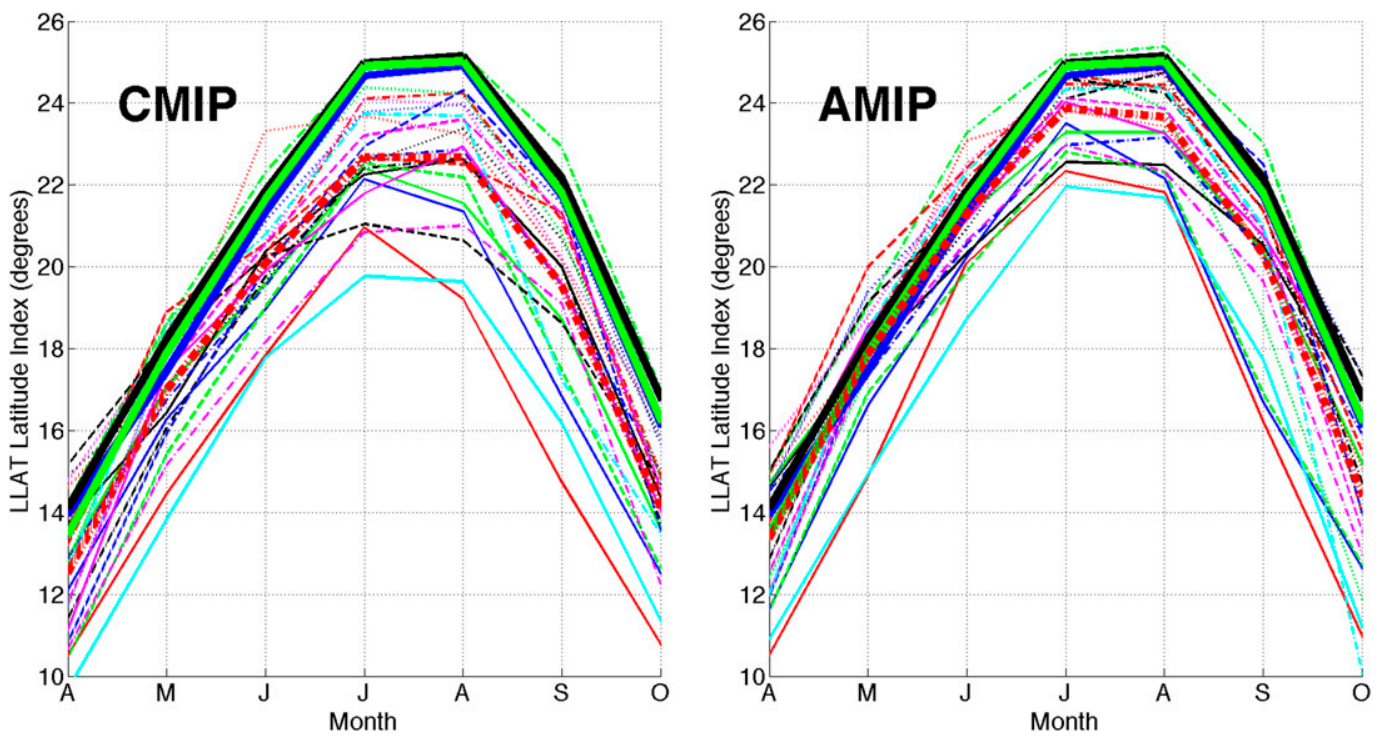

FIG. 3. (left) CMIP and (right) AMIP SHL north-south location as defined by the center of maximum LLAT occurrence frequency for April through October. Each thin line represents a model from the ensemble (indicated in Fig. 4). The ERA-I (thick black line), MERRA (thick blue line), JRA-55 (thick green line), and ensemble average (thick dashed red line) SHL north-south locations are also shown for comparison. 

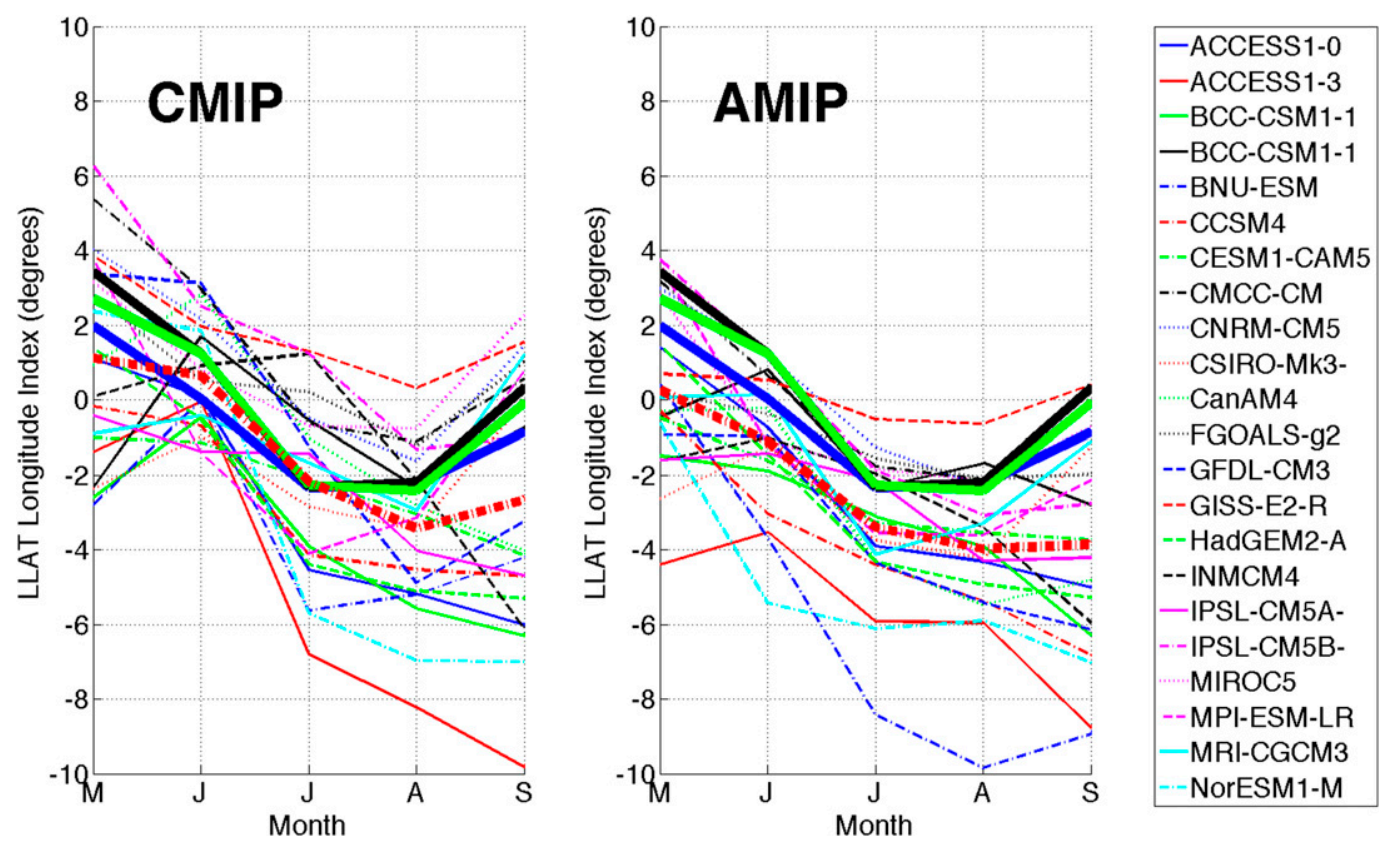

FIG. 4. As in Fig. 3, but for east-west location as defined by the center of maximum LLAT occurrence frequency for May through September.

JRA-55 (thick green line) agree closely for this index and peak during July and August when we expect the SHL to reach its northernmost climatological position.

The indices for the longitudinal position of the SHL (LLAT EW) are shown in Fig. 4. Both the ERA-I (thick black line), MERRA (thick blue line), and JRA-55 (thick green line) place the heat low to the east (positive values of longitude) in May and show how the SHL moves to the west (negative values of longitude) into the middle of the summer (JJA) before moving eastward again in September. This analysis was only performed for May through September owing to a difficulty in tracking the zonal shift in the low outside of the summer months.

\section{4) SAHEL PRECIPITATION}

An index for climatological western Sahel precipitation (PR index) was generated by averaging the monthly precipitation for the region $10^{\circ}-20^{\circ} \mathrm{N}, 15^{\circ} \mathrm{W}-$ $10^{\circ} \mathrm{E}$ for each month and model. Several precipitation indices were tested by altering the averaging region, including varying the longitudinal bounds across the Sahel and found to produce comparable results. Plots of this index are not shown as several studies have largely described this variability (e.g., Vizy et al. 2013).

\section{5) AEW ACTIVITY}

AEW activity (AEW index) is measured as the variance of the daily meridional wind at $850 \mathrm{mb}$ filtered with a 3-9-day bandpass filter (Fyfe 1999). The index for AEW activity was constructed by taking the monthly mean of the filtered daily meridional wind variance over the region delimited by the latitudes $10^{\circ}-20^{\circ} \mathrm{N}$ and the longitudes $20^{\circ} \mathrm{W}-20^{\circ} \mathrm{E}$ for each month and each model. The models CESM1(CAM5), GISS-E2-R, and HadGEM-AO did not provide daily meridional wind output and are not included in the AEW analysis. We looked at both 850- and 700-mb levels when computing the AEW activity and chose the 850-mb level to correspond with Fyfe (1999), although both levels produced a similar signal.

\section{The climatological Saharan heat low bias}

\section{a. Spatial structure}

In Fig. 1, we compare ERA-I and model SHL occurrence frequency maps and show the spatial and temporal structure of the SHL bias. The shading shows the model ensemble mean SHL occurrence frequency subtracted from the ERA-I SHL occurrence frequency. Red colors represent regions where we detect the SHL more frequently in the climate models than in the reanalysis, and blue colors represent areas where the models produce the SHL less frequently than the reanalysis. Similar structures arise when the ERA-I is replaced with MERRA or JRA-55.

Both AMIP (Fig. 1, bottom) and CMIP (Fig. 1, top) models tend to place the SHL farther to the south than the reanalyses and farther to the west, especially during the transition months May and September. Although 

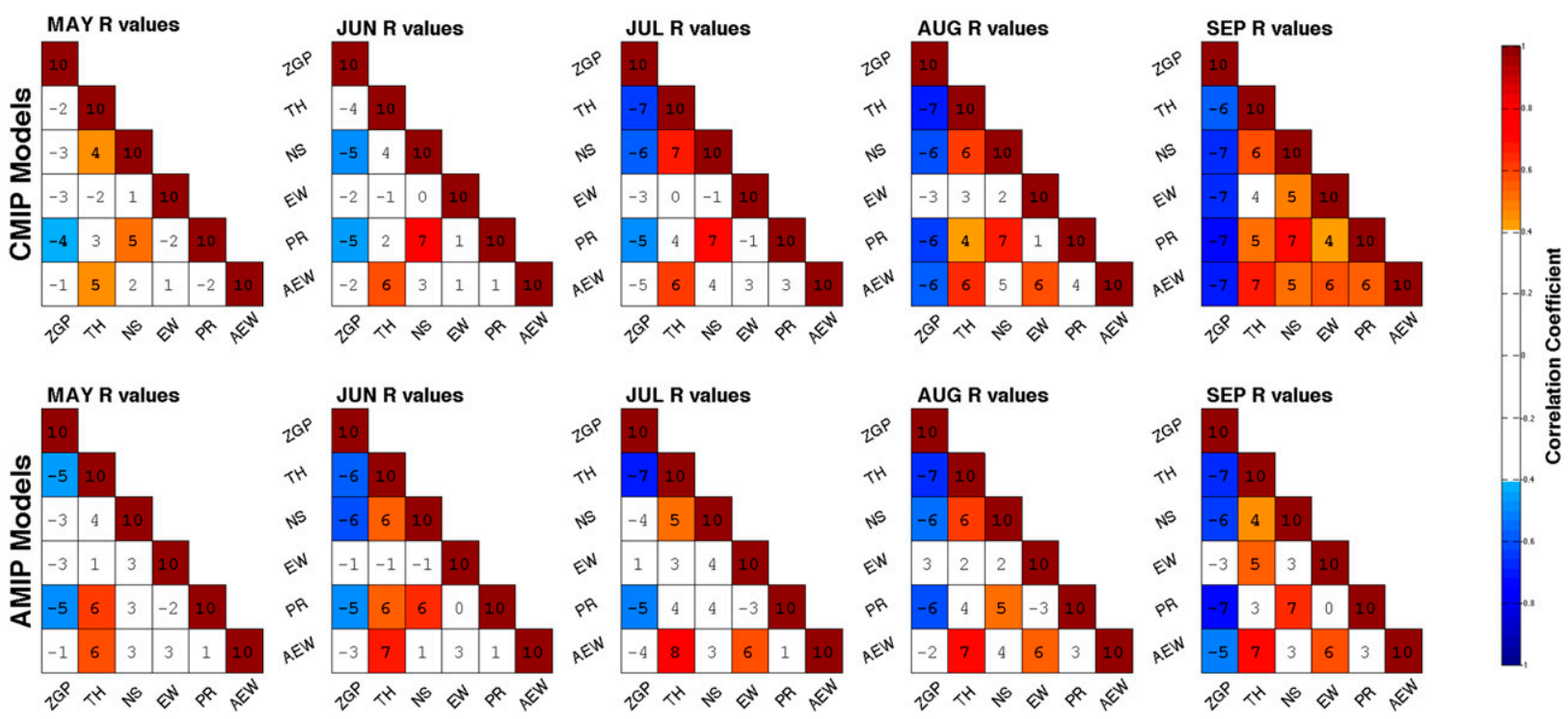

FIG. 5. Correlation table of 925-mb Saharan ZGP, LLAT TH, LLAT NS, LLAT EW, western Sahel PR, and AEW activity for May through September for both (top) CMIP and (bottom) AMIP models. Correlation values are rounded to the nearest tenth and multiplied by 10 to remove the decimal point.

there are some discrepancies between the two ensembles (Fig. S1 in the supplemental material), the overall qualitative similarities between the biases in Fig. 1 suggest that SST biases are secondary to atmospheric and/or land surface mechanisms in explaining the SHL biases that occur in climate models.

The structures shown in Fig. 1 also show that our method detects a region of high LLAT occurrence to the east of the reanalysis SHL, primarily in the CMIP ensemble. In some models this is a zonal extension of the primary low, but in other models it is a secondary low, which forms separately from the traditional SHL. This tendency for some climate models to develop a secondary low would complicate the low-level circulation. This secondary low also complicates the algorithm for generating spatial indices for the SHL location. While this bias may be interesting on its own accord, we are careful not to include it in our index-generating algorithm, by limiting the eastern edge of the domain, so we can focus on the bias associated with the traditional SHL.

\section{b. Relationships between the climatological SHL and West African climate}

To assess the importance of SHL bias for other aspects of the regional climate, we relate the indices for climatological SHL position and strength to the climatological indices described in section 2. Specifically, we correlate the climatological indices across the model ensemble. As such, correlations in this manuscript depict relationships between different aspects of the models' mean states, not internal variability within each model. This approach of investigating mean-state biases via diagnosing relationships across the model ensemble has been used in other studies as well (Delcambre et al. 2013; Langenbrunner et al. 2015).

Figure 5 shows the correlation coefficients ( $R$ values) of the six indices (ZGP, LLAT TH, LLAT NS, LLAT EW, PR, and AEW) with each other for the months of May through September, for the CMIP (top) and AMIP (bottom) simulations. The $R$ values that indicate a statistically significant result (using the two-tailed Studen's $t$ test), at a $95 \%$ confidence interval (CI), are shown in bold. In both the CMIP and AMIP models, many of the indices are not correlated during May and June, but when the SHL fully develops over the Sahara, in July through September, most of the indices show significant correlations, as shown in Fig. 5. We comment on each of the index correlations in detail through the remainder of the section.

The strong similarity between the biases in the AMIP and CMIP models is readily seen along diagonal elements in Fig. 6, which shows the cross correlations between the CMIP and AMIP indices for May through September. Along the diagonal, we see that each index correlates very highly $(0.7-0.9)$ with its corresponding index from the other ensemble. We see strong correlations between CMIP and AMIP models for all months and indices of West African climate, except for the LLAT EW index in June. This lack of correlation in June suggests that SSTs may play a role in the complicated westward transition of the SHL in the beginning on the summer. June also has the largest occurrence of 

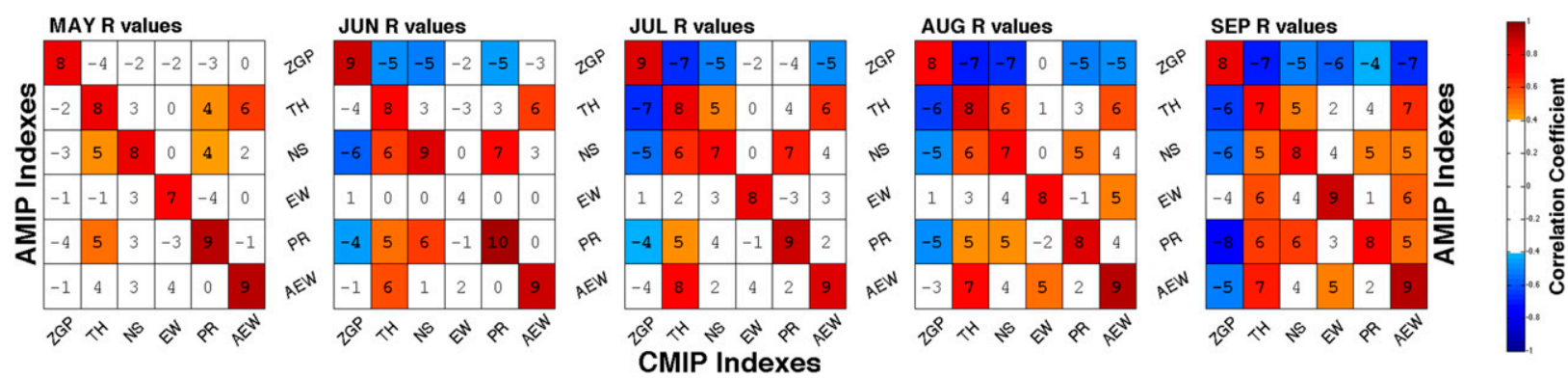

FIG. 6. As in Fig. 5, but for correlation between CMIP and AMIP models.

the secondary low to the east of the SHL region and occurs more often in the CMIP models than the AMIP models (Fig. S1), which complicates the analysis of the LLAT EW index in early boreal summer. The overall strong correlations ( $>0.7$ for almost all indices) between the CMIP and corresponding AMIP indices in Fig. 6 (diagonal elements) demonstrate that SST biases do not play a primary role in the SHL biases. Roehrig et al. (2013) limited their analysis of the WAM to the AMIP models to avoid the strong SST biases in the Gulf of Guinea, but our analysis shows that understanding how the SHL affects the WAM forcing is not hindered by SST biases, at least in a multimodel analysis.

The LLAT TH index represents the development of the climatological SHL. Although both the CMIP and AMIP ensemble average of the LLAT TH index (red dotted line in Fig. 2) show the same behavior as the reanalyses, both ensembles exhibit extreme variability in the LLAT TH values, although AMIP models exhibit less variability and produce an ensemble average slightly closer to the reanalysis values than the CMIP models. Figure 2 shows that many models produce a weaker SHL than the reanalyses and also have difficulty producing the proper seasonal evolution of the SHL strength (Fig. S2).

The ZGP index represents a subtly different aspect of the strength of the monsoon circulation associated with the SHL. Since the ZGP index involves a difference between geopotential heights in the SHL region and over the entire tropics, a mean tropical geopotential height bias will be removed from the ZGP index. As expected, the ZGP and LLAT TH indices are strongly, negatively correlated during July, August, and September (Fig. 5), when the heat low is completely located over the Sahara, because of the geographical constraint used when computing ZGP. For the remainder of the paper, we will focus on the LLAT TH index to describe the SHL strength, as we are more concerned about the local representation of the heat low.

Almost all of the AMIP and CMIP models place the climatological heat low farther south than the reanalyses (Fig. 3; see also Fig. 1). We ordered both ensembles by the magnitude of the JJA average LLAT NS index and found that there was no relationship with model resolution. The AMIP ensemble exhibits less variability and reproduces the reanalyses more closely than the CMIP models, which may show some influence of SSTs on the SHL latitudinal position. However, the LLAT NS index from the CMIP models is significantly correlated with the LLAT NS from the AMIP models (Fig. 6) for the months May through September, which suggests atmospheric biases are primarily responsible for the inability of models to place the SHL as far to the north as the reanalyses.

Both CMIP and AMIP models have difficulty reproducing the longitudinal evolution of the SHL shown in the reanalysis (Fig. 4). AMIP simulations tend to place the SHL much farther to the west from May to September than the reanalyses. The ensemble average of the CMIP models matches the reanalysis heat low position for May through July (although variations are strong across models), but it places the SHL too far west in August and September. The two SHL location indices, LLAT NS and LLAT EW, are not strongly correlated with each other, suggesting different dynamical mechanisms are responsible for these biases (Fig. 4). Instead, strength and latitudinal location are related, in the sense that models that produce heat lows with a higher LLAT TH also tend to produce heat lows that are farther northward (Fig. 5), especially during July, August, and September. The LLAT TH index does not appear to be significantly correlated with the LLAT EW index (Fig. 5).

Models that place the SHL farther to the north produce more precipitation in the Sahel region in both the AMIP and CMIP simulations during the entire summer (Fig. 5). This relationship is strongest in the CMIP models, where the correlation between the north-south position of the SHL and Sahel precipitation is 0.7 for June through September. When the SHL is farther to the north, its circulation pattern is also shifted north, which allows moisture rich tropical air to be advected farther inland, resulting in greater precipitation across the area. This connection between the SHL and moisture will be 
explored further in section 5. The LLAT EW index explains very little of the variance in precipitation across the models.

Models that tend to place the SHL farther to the east during July, August, and September also have more AEW activity. Given that AEWs are common seeding disturbances for tropical cyclones, this relationship may be important for understanding tropical cyclone development in GCMs, as the majority of models actually place the SHL too far west. The LLAT TH index explains the most variance in the AEW activity, especially in the AMIP simulations. The LLAT NS index explains very little of the variance in the AEW activity across the models, though the LLAT NS index may result in variations in AEW location that are not captured by the AEW index.

In summary, we have seen that both metrics for heat low strength (LLAT TH and ZGP) are correlated during summer months, and the index we have selected for this analysis, LLAT TH, is correlated with LLAT NS, Sahel precipitation, and AEW activity. Models tend to place the SHL too far to the south, which strongly correlates with less Sahel precipitation. The LLAT EW index is correlated with AEW activity, especially toward the end of summer when models tend to place the SHL too far to the west.

\section{Relationship between the model SHL bias and the large-scale and local climatological bias}

In section 3, we identified strong biases in the climatological location of the SHL that were similar in both AMIP and CMIP models, suggesting that atmospheric mechanisms are dominant over oceanic ones in producing such biases. In this section, we further explore the relationship between the simulated climatological SHL and the large-scale circulation and local state of the atmosphere across the models. We are interested both in features that are forced by the SHL and in those that could force the SHL. Understanding what spatial structures covary with climatological SHL variability across the models will allow us to formulate testable hypotheses on the sources of the apparent bias. Statistical significance is inferred using the Student's $t$ test on the correlation, and we discuss only features that are statistically significant and of sufficiently large scale to be deemed physical.

\section{a. Local radiative balance and moisture}

Since the SHL may be fundamentally driven by surface temperatures and local forcings, understanding the flux balance local to the Sahara and Sahel may be the key to understanding how these SHL biases are being generated. The regression with surface temperature (Fig. S5 in the supplemental material) does not indicate a strong relationship between how hot the Saharan surface is and how well developed or how far north the SHL is. Instead, it is apparent that the energy fluxes into the atmosphere are key. Surface turbulent fluxes play some role in affecting the position or the depth of the SHL (viz., latent heat fluxes at the northern edge of the Sahel affect the NS index, and sensible heat fluxes in the Sahara interior affect the intensity), but radiative fluxes appear to be dominant. From the CMIP5 ensemble, we computed radiative budgets at the surface and top of atmosphere and for the total atmospheric column (derived as net top-of-atmosphere flux components minus net surface flux components). These were then regressed across the models onto the SHL indices. Inspection of the various flux components (Fig. S6) indicates that column shortwave (SW) absorption is the largest contributor to changes in the atmospheric column heating. JJA SW column absorption regressed onto both the JJA LLAT TH and NS indices for both CMIP and AMIP model ensembles is shown in Fig. 7 (a vertical distribution of SW heating is not available for analysis). In these plots, the model ensemble mean is shown in the shading, with the regression coefficients indicated with the open contours. As shown in Fig. 7, both CMIP (left) and AMIP (right) show an increase in SW absorption over the entirety of North Africa, for both regressions onto LLAT TH (top) and LLAT NS (bottom). The regression onto the LLAT TH index is not significant (gray shaded regions denote statistical significance in Fig. 7) for a large region over West Africa, with the largest region of increased SW absorption over the Ethiopian highlands. In contrast, the regression onto the LLAT NS index shows the greatest amount of column SW absorption over the southwestern corner of the SHL region, where we see the largest SHL bias.

The climatological water vapor concentration also varies strongly across CMIP5 models and strongly influences the radiative budget. Figure 8 shows the zonal cross section of specific humidity averaged from $10^{\circ} \mathrm{W}$ to $10^{\circ} \mathrm{E}$ regressed onto both the JJA LLAT TH (top) and NS (bottom) indices. A large increase in low-level (below $800 \mathrm{mb}$ ) specific humidity across the Sahel and Southern Sahara $\left(10^{\circ}-20^{\circ} \mathrm{N}\right)$ is consistent with the increased precipitation in the Sahel and with the idea that models that produce heat lows that are stronger and shifted farther northward generate a circulation that brings more water vapor into the Sahel region. This is consistent with Vizy et al. (2013), which showed an increase in Sahel in climate projections was associated with a strengthening of the SHL; however, we note that 

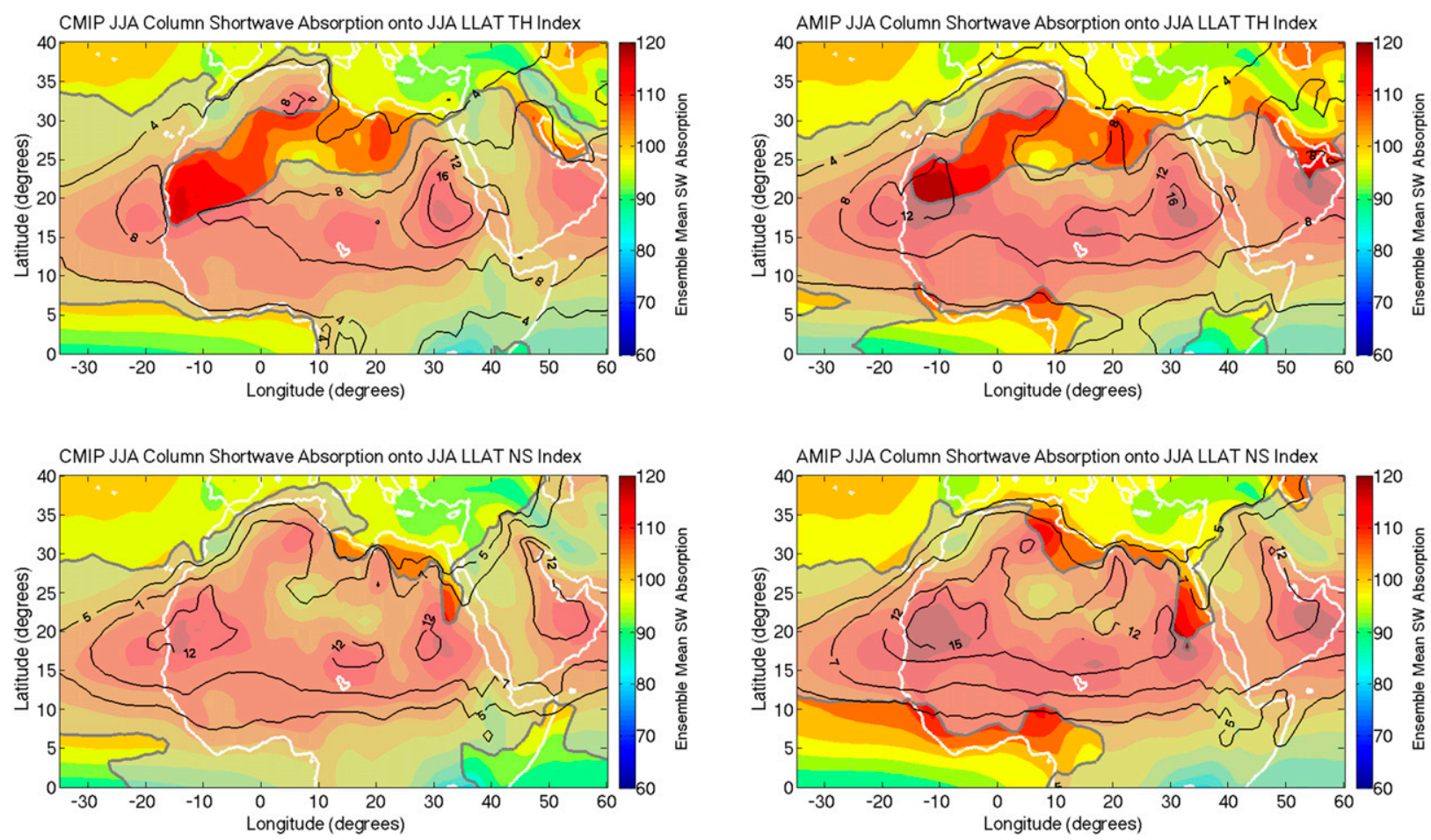

FIG. 7. JJA column shortwave absorption $\left(\mathrm{W} \mathrm{m}^{-2}\right.$ ) regressed onto both (top) the JJA LLAT TH and (bottom) the JJA LLAT NS index for both (left) CMIP and (right) AMIP ensembles as shown by the black contours. The ensemble average column shortwave absorption is shown by the colored shading. Statistical significance at a $95 \%$ confidence interval is indicated by the gray shaded region.

the increase in low-level moisture is stronger in the LLAT NS regressions than in the LLAT TH regressions.

\section{b. Large-scale upper-level wind and sea level pressure}

Large-scale biases in climate models may generate the SHL bias through transport of moisture, dust, and sensible energy into the Saharan region. In this section, we perform lagged regressions to identify large-scale features present before the monsoon season that covary with SHL biases at the end of the summer.

We begin by looking at SLP across the North Atlantic, as a previous study (Barandiaran and Wang 2014) identified a teleconnection between Atlantic SLP and Sahel precipitation in CFSR. When June SLP is regressed onto the August LLAT NS and LLAT TH indices (Fig. 9), both AMIP and CMIP models produce patterns of high SLP across the central Atlantic around $30^{\circ} \mathrm{N}$, with low SLP both above $45^{\circ} \mathrm{N}$ and off the west coast of Africa. This dipole pattern is similar to the positive phase of the North Atlantic Oscillation (NAO) (Barnston and Livezey 1987). Although it does not exactly match the canonical or summer NAO (Folland et al. 2009), we expect it to signify a shift in the upperlevel winds in a similar manner. Models that produce this climatological pattern in the early summer months tend to develop a heat low that is stronger and located farther to the north in subsequent months. This is consistent with the variability study of Folland et al. (2009), which linked the summer NAO with Sahel rainfall variability. Although SLP distributions are strongly connected to SSTs, the pattern of SLP biases that covary with the SHL indices is similar in both the AMIP and CMIP simulations (the amplitude is stronger in the AMIP ensemble because of the wide range of basic states in the CMIP models). Thus, we focus on largescale atmospheric patterns that covary with SLP and directly investigate upper-level zonal winds (Delcambre et al. 2013).

Figure 10 shows a Hovmöller diagram of zonally averaged $250-\mathrm{mb}$ zonal winds regressed onto the August LLAT NS index. We zonally average over $75^{\circ} \mathrm{W}-$ $75^{\circ} \mathrm{E}$ in order to best represent the large-scale wind structure that could influence North Africa. The model ensemble zonally averaged $250-\mathrm{mb}$ winds are shown in the shading with the regression coefficients in the open contours. This analysis was also done for only the Atlantic region and indices averaged for JJA with comparable results (not shown). AMIP and CMIP models that produce the climatological SHL farther to the north during the summer tend to have stronger, 

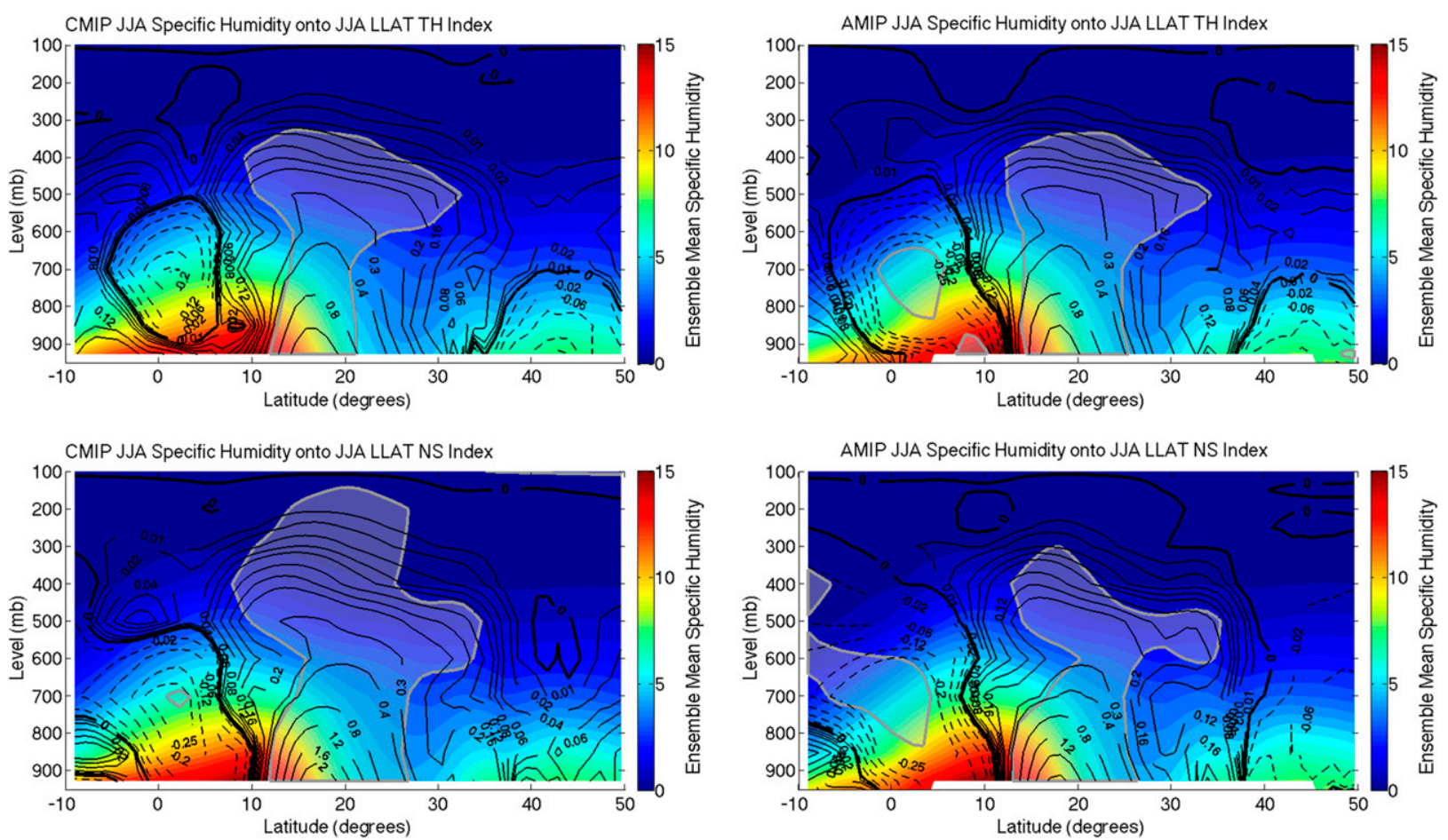

FIG. 8. As in Fig. 7, but for zonally averaged specific humidity (from $10^{\circ} \mathrm{W}$ to $10^{\circ} \mathrm{E} ; \mathrm{g} \mathrm{kg}^{-1}$ ). The ensemble average zonally averaged specific humidity is shown by the shading.

farther-northward-shifted 250-mb jets across the midlatitudes. This is evident mid-March through October but is particularly strong during the transitional seasons before and after the monsoon, with correlation coefficients reaching values of 0.7 in June and September. However, during the summer months the strongest signal shifts to the tropics, possibly because outflow from the monsoon and the anticyclonic upper-level circulation associated with the SHL are able to increase the strength of the 250-mb tropical easterly jet.

Spatial patterns of early summer upper-level zonal winds regressed onto August LLAT NS and August LLAT TH indicate that a stronger and farther northward SHL, tends to follow a midlatitude jet that extends farther across the Atlantic in early summer months. This asynchronous relationship, explored with the lagged regressions in this section, shows large-scale circulations present before the onset of the monsoon are connected with the development of the SHL bias.

\section{c. Precipitation and low-level winds}

Finally, we investigate how the SHL indices are connected with biases in precipitation and winds during the height of the monsoon season (August). Figure 11 shows the model ensemble mean location of precipitation in August for the CMIP (top) and AMIP (bottom) models in the white open contours, with the model ensemble mean 925 -mb winds shown in the gray vectors. The spatial structures are similar in both July and September and for the JJA averaged fields and indices. They are also similar when regressed onto the LLAT TH index. Across the Sahel, stronger precipitation is associated with northward-shifted heat lows as seen in the shading in both AMIP and CMIP ensembles. This increased precipitation is associated with the strengthening of westerly winds (shown in the black vectors), which transport moisture into the region, corresponding with the increased low-level moisture across the Sahel described earlier.

On a larger scale, across East Africa and India, we see an increase in precipitation associated with models that place the SHL farther northward (Fig. 11). Latent heating and outflow associated with convection and increased tropical precipitation generate stationary Rossby waves. Regression of JJA 250-mb winds and heights (Fig. S7 in the supplemental material) onto the JJA LLAT NS index shows elevated heights and anticyclonic anomalies west of the convection centers in East Africa and India, in both AMIP and CMIP ensembles. This follows the framework of Rodwell and Hoskins (1996); however, the scale of the generated waves does not appear to significantly impact West Africa.

The significant connection of the strength and position of the climatological SHL with precipitation outside 
CMIPJUN Sea Level Pressure onto AUG LLAT TH Index

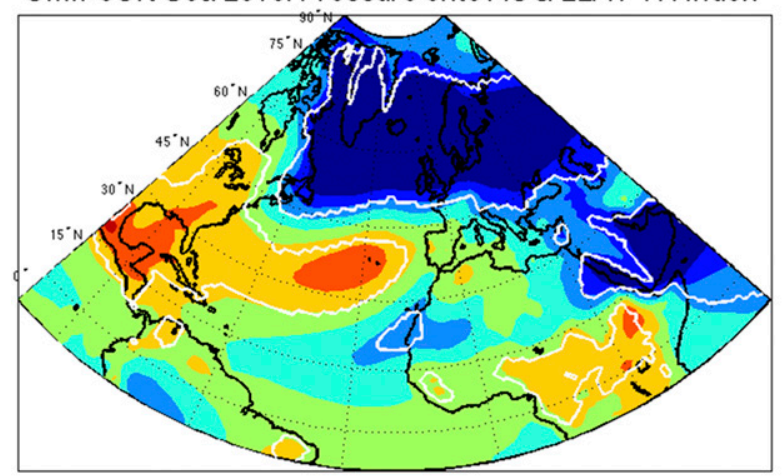

CMIPJUN Sea Level Pressure onto AUG LLAT NS Index

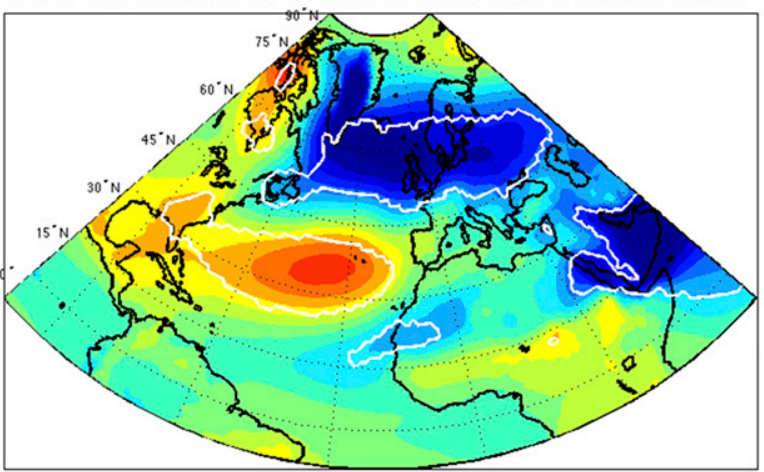

AMIPJUN Sea Level Pressure onto AUG LLAT TH Index

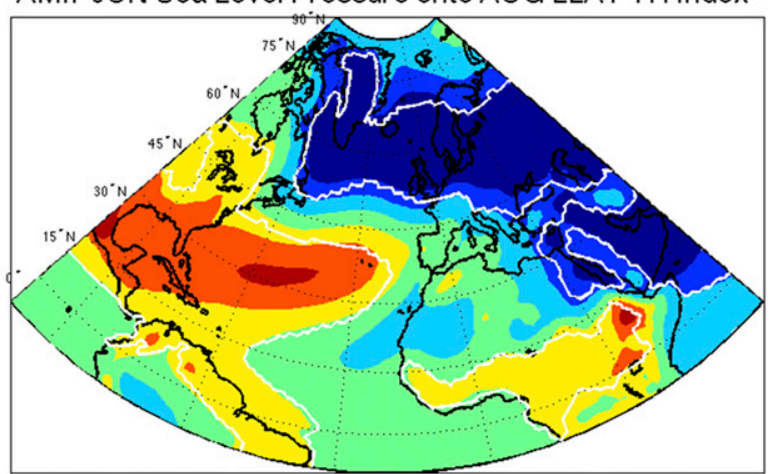

AMIPJUN Sea Level Pressure onto AUG LLAT NS Index

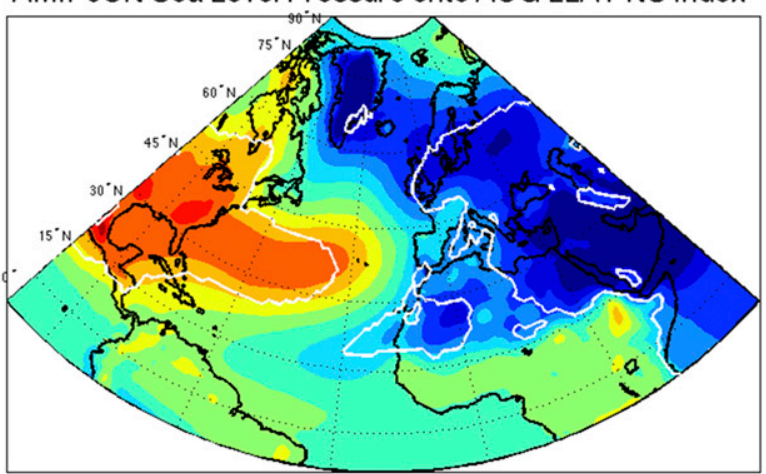

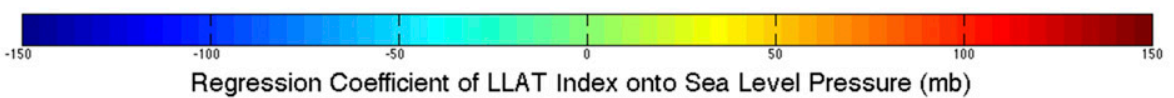

Regression Coefficient of LLAT Index onto Sea Level Pressure (mb)

FIG. 9. June SLP (mb) regressed onto both (top) the August LLAT TH and (bottom) the August LLAT NS index for both (left) CMIP and (right) AMIP ensembles. Regions of statistical significance are demarked by the white contours.

West Africa may also indicate that the simulation of the SHL is linked to the broader tropical circulation and that local biases are related to biases in the simulation of the zonal mean ITCZ and the associated Hadley cell. In particular, a northern shift of the SHL is associated with a northern shift of zonal mean precipitation in the entire sector (see, in the CMIP simulations, the increased rainfall in India and the meridional shift in the Atlantic and, in the AMIP simulations, the more pronounced shift in the Indian Ocean). The dynamics of the zonal mean ITCZ have been described in terms of interhemispheric differences in the atmospheric heat budget and, as an approximation, the interhemispheric temperature differences (Frierson et al. 2013; Schneider et al. 2014). In the CMIP ensemble the JJA LLAT NS index is correlated with the annual interhemispheric temperature difference with a correlation coefficient of 0.72 (the relationship is not as apparent in the AMIP ensemble, in which SST cannot adjust to heat fluxes).
This suggests that biases in the global energy budget might explain a significant portion of the variance in the SHL bias in the coupled models.

Finally, the regression of precipitation onto the LLAT NS index (Fig. 11) indicates a different behavior between the AMIP and CMIP ensembles across the Atlantic basin. In the CMIP models, a clear northward ITCZ shift is associated with models that place the SHL farther northward. These models also show a relaxation of the trade winds and cross-equatorial flow across the Atlantic, which resembles the Atlantic meridional mode (AMM) (Chiang and Vimont 2004). In contrast, the AMIP ensemble shows an eastward shift in the precipitation maximum for models that place the SHL farther to the north, even though the relaxation of the trade winds remains. We attribute this to the fact that the SSTs in the AMIP ensemble cannot respond to the atmospheric forcing. We also note that the different patterns of rainfall anomaly in the Atlantic suggest that the climatological position 

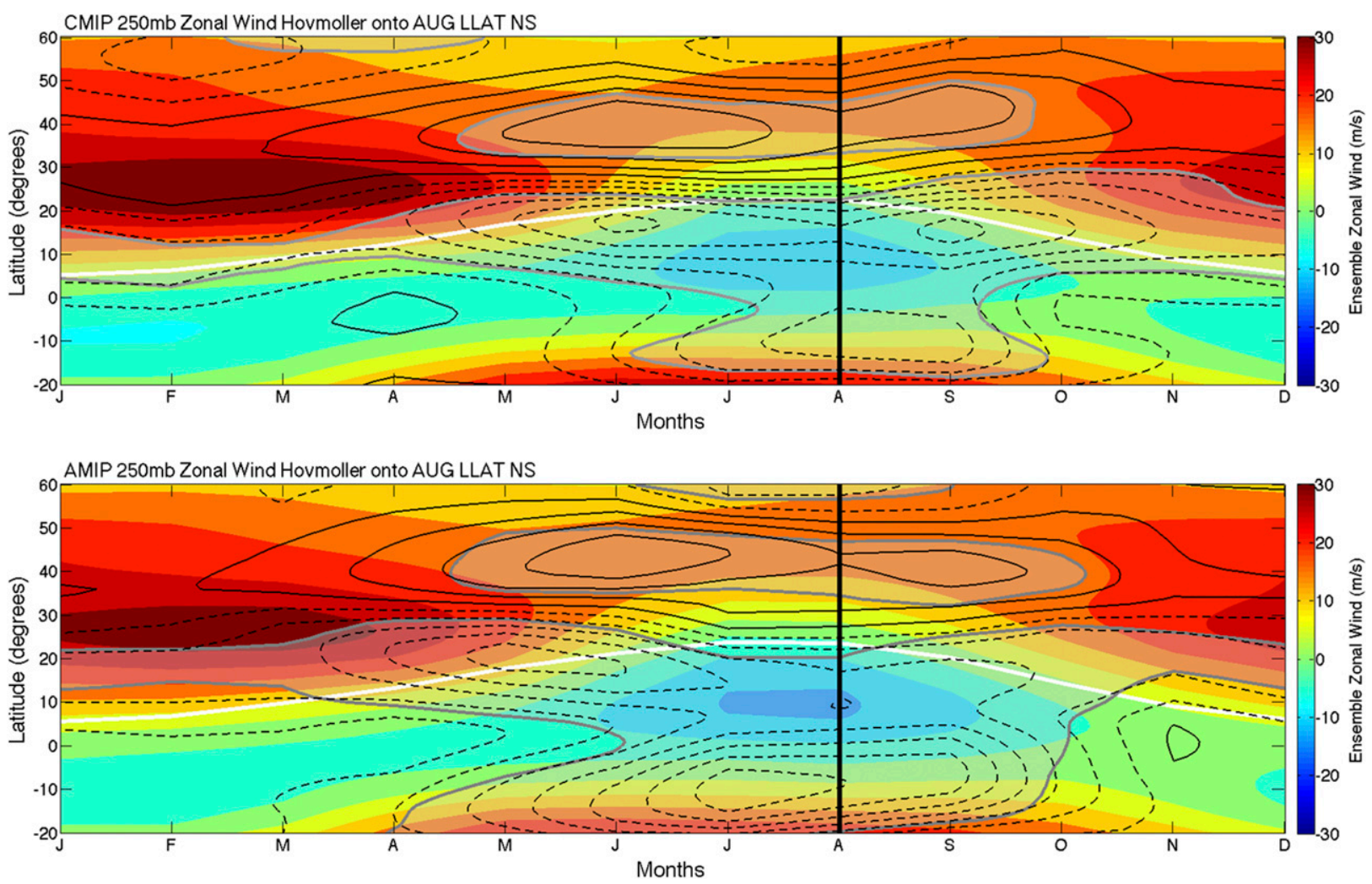

FIG. 10. Zonally averaged $250-\mathrm{mb}$ zonal wind $\left(75^{\circ} \mathrm{W}-75^{\circ} \mathrm{E} ; \mathrm{m} \mathrm{s}^{-1}\right)$ regressed onto the August LLAT NS index for both (top) CMIP and (bottom) AMIP ensembles during each month of the year along the $x$ axis. the ensemble mean zonally averaged 250-mb zonal wind is indicated by the color shading. The thick white line represents the ensemble average LLAT NS index value. The regression coefficients are shown by the solid (positive) and dashed (negative) open contours, with intervals of $0.5 \mathrm{~m} \mathrm{~s}^{-1}$. Statistical significance at a $95 \%$ confidence interval is indicated by the gray shaded region.

of the SHL is unlikely to be strongly affected by circulation anomalies directly forced by the Atlantic marine ITCZ.

\section{Discussion}

This study is exploratory in nature, with a focus on describing the SHL bias in CMIP5 models and how climatological aspects of the models covary with the SHL bias. In this section, we present hypotheses concerning the mechanisms that create these relationships, though future work will be needed to test these hypotheses.

\section{a. How does the climatological SHL location and position in climate models respond to local forcing?}

Our analysis of SW heating and moisture (section 4a) shows that models with northward SHL biases have enhanced SW absorption (Fig. 7) and increased lowlevel specific humidity (Fig. 8). These moisture anomalies extend into the Sahara to around $25^{\circ} \mathrm{N}$, where moisture can develop the Saharan water vaportemperature (SWAT) feedback described in Evan et al. (2015). The SWAT feedback operates through the import of moisture into the region, which generates more SW absorption and more LW emission and, in the balance, generates a stronger SHL and further strengthens the low-level circulation bringing more moisture into the region.

This low-level moisture signal is only significant between $10^{\circ}$ and around $25^{\circ} \mathrm{N}$, though, which cannot completely account for the column SW absorption signal we see across the entire Sahara north of $25^{\circ} \mathrm{N}$. At higher levels, between 300 and $600 \mathrm{mb}$, the specific humidity increase extends from $10^{\circ}$ to $35^{\circ} \mathrm{N}$. These upper-level humidity anomalies might be a consequence of precipitation anomalies continually fluxing detrained water vapor from the southern band or transport across the Mediterranean region as described by Park et al. (2015). We do not know where in the column the SW absorption is happening, nor do we fully understand how upper-level SW absorption, associated with increased moisture, might alter the SHL and the circulation at lower levels.

Another possibility for the enhanced SW absorption in Fig. 7 may be changes in aerosol forcing. For example, 

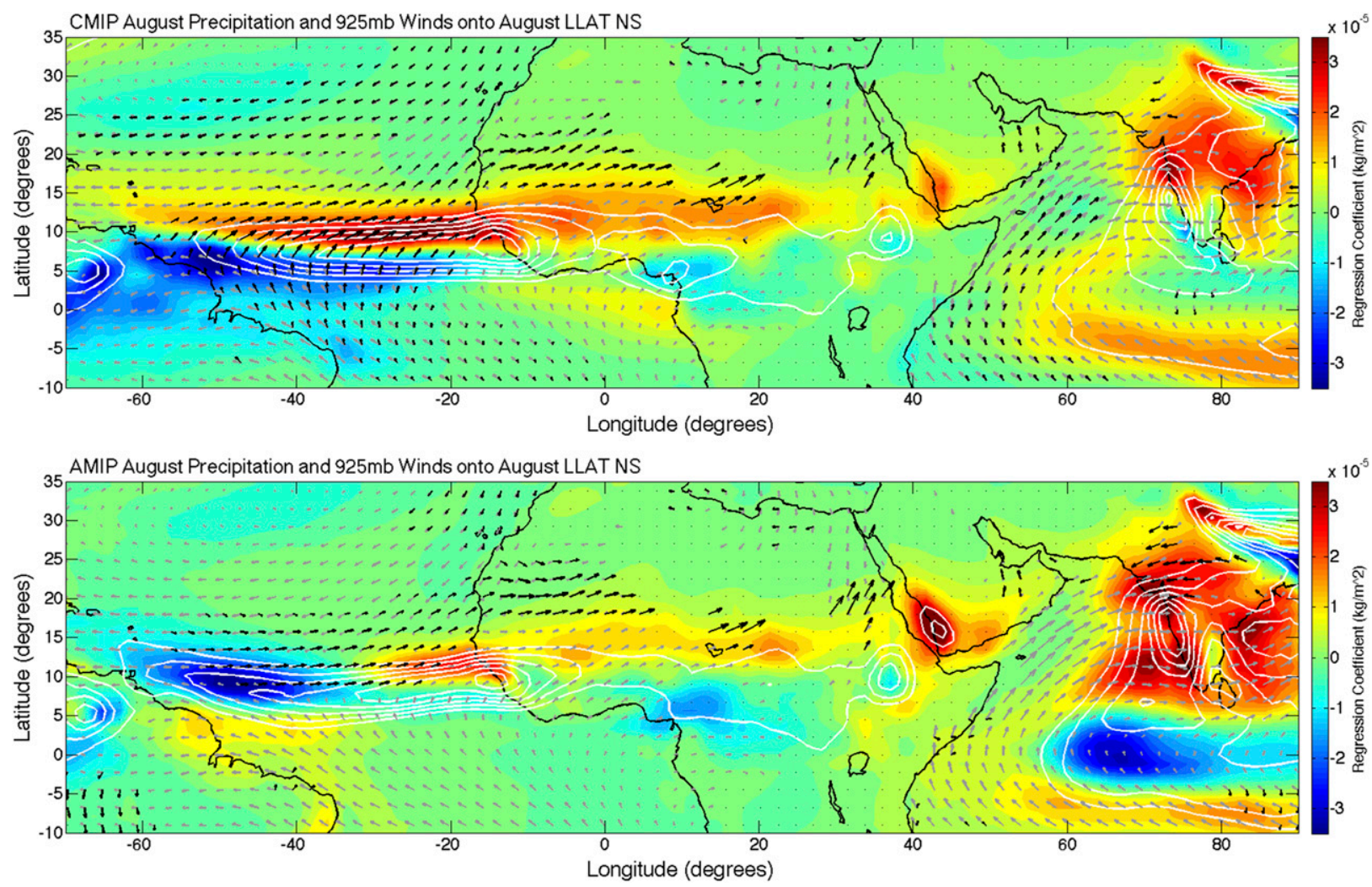

FIG. 11. August 925-mb winds and precipitation regressed onto the August LLAT NS index for both (top) CMIP and (bottom) AMIP ensembles. Gray vectors indicate the ensemble mean circulation. The black vectors are plotted only where the correlation between the $925-\mathrm{mb}$ wind and the LLAT NS index is $>0.43(95 \% \mathrm{CI})$. The color shading shows the regression coefficient for precipitation $\left(\mathrm{kg} \mathrm{m}^{-2}\right)$. The ensemble mean precipitation $>6 \times 10^{-5} \mathrm{~kg} \mathrm{~km}^{-2}$ is indicated by the white contours.

an observational study by Lavaysse et al. (2011) showed the importance of dust on the radiative budget and resulting SHL circulation. CMIP5 models handle dust in several different ways and have difficulty properly representing features of North African dust emission and transport (Evan et al. 2014). Of the models used in this study, only half of them output the aerosol fields needed to investigate how the SHL bias is connected to model dust representation, so we were unable to look at dust and aerosol forcing in depth.

\section{b. How might large-scale extratropical dynamics influence the SHL bias in position and strength?}

Transport of moisture and sensible energy by the midlatitude jet into the northern Sahara has been shown to influence the SHL on synoptic time scales (Vizy and Cook 2009; Chauvin et al. 2010; Lavaysse et al. 2010a,b), which is then reflected in the WAM strength and onset. For example, Lavaysse et al. (2010b) showed that extratropical waves can cause the heat low to pulse on a 14-15-day time scale, as they inject cooler midlatitude air into the Saharan region. While these previous studies focus on synoptic time scales, similar mechanisms may impact the climatological representation of the SHL in the CMIP models. We hypothesize that northward-shifted storm tracks associated with the jet are unable to transport as much cool extratropical air into the Saharan region, allowing for a deeper SHL to develop. Fully understanding the mechanisms that allow these large-scale atmospheric patterns to interact with the SHL will require further work, but the strong relationship between the midlatitude jet and the SHL bias (shown in section $4 \mathrm{~b}$ ) allows us to hypothesize how shifting storm tracks could influence the SHL through import of temperature and moisture.

\section{c. How is the SHL bias connected to the AEJ and AEW activity?}

Increased precipitation across the Sahel (shown in section 4c) is also associated with surface cooling, which strengthens the meridional temperature gradient across the Sahel. We regressed August 700-mb zonal winds onto the August LLAT NS and LLAT TH indices (Fig. S5) to see how the change in temperature gradient from the altered hydrological cycle might affect the AEJ. In both 
the AMIP and CMIP ensembles, models that produce the SHL stronger and farther northward, tend to produce a 700-mb AEJ that is stronger and farther northward, in accordance with the relationship between the meridional temperature gradient and the AEJ position and strength described in Cook (1999). The connection between the SHL bias and the AEJ may explain the connection to the models' AEW activity (see the strong correlation between LLAT TH and AEW index in Fig. 5), as the upperlevel anticyclonic flow associated with the SHL helps generate the AEJ, in which the AEWs are embedded.

\section{d. Are tropical precipitation biases responsible for the bias in the SHL?}

We often consider the precipitation response to the SHL, the strong correlation between the SHL bias and an increase in precipitation across the tropics (Fig. 11), however, might indicate that the SHL bias is forced through a teleconnection to more remote regions of precipitation. The increased precipitation to the east of West Africa, for example, generates stationary Rossby waves that could warm the Sahara through adiabatic descent on the southern flank of the midlatitude jet (Rodwell and Hoskins 1996) and influence the SHL. However, we do not think this is the case, as the upperlevel anomaly associated with the stationary wave (Fig. S7) does not extend far enough across Africa.

A teleconnection to the tropical Atlantic mean-state bias also seems unlikely, as the tropical Atlantic precipitation structures associated with the SHL bias in the CMIP and AMIP simulations (Fig. 11) are very different. The meridional shift we see in the Atlantic ITCZ in the CMIP models could be forced by the SHL location and strength, through initiating the wind-evaporation-SST (WES) feedback (Xie and Philander 1994) on the east side of the basin. It is also possible that a large-scale pattern may be connected with both the ITCZ shifts and the SHL biases seen in the climate models, with neither the ITCZ location nor the SHL position directly forcing each other.

The relationships between the SHL bias and the spatial structures we have identified in this paper could be the result of serial correlations with a global-scale bias (e.g., the well-known bias in the global atmospheric heat budget). The strong agreement of several reanalyses in the placement of the SHL (Figs. 3 and 4), even while they disagree about several local aspects of West African climate, also suggests that local mechanisms might be secondary to global forcings.

\section{Conclusions}

In this paper, we investigate how model biases in the strength and position of the climatological SHL are connected with each other, as well as with other indices of West African climate and large-scale atmospheric features. We use the lower-level atmospheric thickness (LLAT) method of Lavaysse et al. (2009) to define the SHL position and strength for 22 climate models from CMIP5 and compare them to reanalyses ERA-I, MERRA, and JRA-55. We show that the models tend to place the SHL farther to the south and farther to the west than reanalyses. These climatologies of the SHL indices are similar for coupled (CMIP) and fixed SST (AMIP) ensembles, suggesting that atmospheric and land surface mechanisms are primarily responsible for the biases.

Indices of both strength and position of the SHL are strongly correlated across the models with several aspects of West African climate, showing that they are useful metrics for exploring climate model biases. The index for meridional position (LLAT NS) explains a large amount of variance in the Sahel precipitation across the models, in the sense that models that simulate the SHL farther to the north produce more Sahel precipitation. SHL strength (LLAT TH) is also positively correlated with Sahel precipitation. The zonal position (LLAT EW) index is correlated with AEW activity but not with precipitation.

We investigate both large-scale and local atmospheric mechanisms via the covariance of climatological patterns with the SHL indices across the ensemble in order to develop hypotheses on what controls the model SHL behavior at the climatological scale. Both AMIP and CMIP models have more column shortwave absorption across the Sahara and Sahel for stronger and more northward SHLs. This increased shortwave radiative absorption balances the increased longwave cooling and may be explained by the increased specific humidity in the Sahara associated with models that produce the SHL stronger and farther to the north. On a hemispheric scale, a positive NAO-like pattern in the Atlantic SLP and a shift in the regional upper-level jet during the early monsoon season correlates with SHL strength and latitude later in the monsoon season, suggesting that these structures may influence West African climate through the SHL. Across the tropics, we see an increase in monsoon precipitation associated with a stronger and farther northward SHL, not just in West Africa but in India and the Arabian Peninsula as well. Over the Atlantic, a northward shift in the SHL is accompanied by a northward shift in the ITCZ in CMIP models (which allow the ocean to respond to surface forcing).

Although this study is primarily diagnostic in scope, its results provide guidance for future research on biases in North African climate. The strong similarity between biases in the CMIP and AMIP model archives argue, in 
our opinion convincingly, that SST biases are not primarily responsible for biases in the SHL. This is a somewhat surprising result, as the SHL is understood as an important mechanism forcing Sahel precipitation, and many recent studies have emphasized the role of SSTs in understanding the intraseasonal-interdecadal variability and trends in Sahel precipitation (Giannini et al. 2013; Liu et al. 2014; Rodríguez-Fonseca et al. 2015; Park et al. 2015). Yet there is not necessarily a contradiction, as SST and atmospheric forcings can well coexist and each explain a sizable, but not dominant, fraction of the SHL and Sahel rainfall variance. We note as a relevant aside that other studies have linked changes in the midlatitude circulation to changes in tropical and subtropical climate, even independently of changes in SST (e.g., Previdi and Liepert 2007; Kang et al. 2011). Furthermore, the strong differences between the structure of tropical Atlantic precipitation associated with the SHL bias in the CMIP and AMIP simulations (Fig. 11) suggest that SHL biases are not a teleconnected response to tropical Atlantic mean-state biases. Instead, the strong similarity between the CMIP and AMIP simulations' subtropical and midlatitude circulation structures related to the SHL bias (Figs. 9-11) point toward large-scale atmospheric processes in generating the SHL bias. Biases in the local column SW absorption over the SHL region are likely related to differences in how moisture and dust are represented in the models, which may in turn be related to biases in the advective processes associated with midlatitude circulation, or to increased moisture export to the region from increased Sahel precipitation. These hypotheses should be tested with additional model experiments.

Acknowledgments. This research was supported by NSF Grants ATM-0849689 and 1463970 and the University of Wisconsin Climate, People, and Environment Program. MERRA data used in this study have been provided by the Global Modeling and Assimilation Office (GMAO) at the NASA Goddard Space Flight Center through the NASA GES DISC online archive. JRA-55 data used in this study are from the Japanese 55-year Reanalysis (JRA-55) project carried out by the Japan Meteorological Agency (JMA). ERA-Interim data were provided courtesy of ECMWF. We acknowledge the World Climate Research Programme's Working Group on Coupled Modelling, which is responsible for CMIP, and we thank the climate modeling groups (listed in Table 1) for producing and making available their model output. For CMIP the U.S. Department of Energy's Program for Climate Model Diagnosis and Intercomparison provides coordinating support and led development of software infrastructure in partnership with the Global
Organization for Earth System Science Portals. Thanks to Amato Evan for help early in the project, to Megan Kirchmeier-Young for assisting with timestamping the daily wind data, and to the editor and several reviewers whose comments and suggestions helped greatly improve and clarify this manuscript.

\section{REFERENCES}

Arora, V. K., and Coauthors, 2011: Carbon emission limits required to satisfy future representative concentration pathways of greenhouse gases. Geophys. Res. Lett., 38, L05805, doi:10.1029/ 2010GL046270.

Barandiaran, D., and S.-Y. Wang, 2014: The missing teleconnection between the North Atlantic and the Sahel precipitation in CFSv2. Atmos. Sci. Lett., 15, 21-28, doi:10.1002/asl2.457.

Barnston, A. G., and R. E. Livezey, 1987: Classification, seasonality and persistence of low-frequency atmospheric circulation patterns. Mon. Wea. Rev., 115, 1083-1126, doi:10.1175/ 1520-0493(1987)115<1083:CSAPOL > 2.0.CO;2.

Bentsen, M., and Coauthors, 2013: The Norwegian Earth system model, NorESM1-M-Part 1: Description and basic evaluation of the physical climate. Geosci. Model. Dev., 6, 687-720, doi:10.5194/gmd-6-687-2013.

Bi, D., and Coauthors, 2013: The ACCESS coupled model: Description, control climate and evaluation. Aust. Meteor. Oceanogr. J., 63, 41-64.

Biasutti, M., A. Sobel, and Y. Kushnir, 2006: AGCM precipitation biases in the tropical Atlantic. J. Climate, 19, 935-958, doi:10.1175/JCLI3673.1.

__ _ _ , and S. J. Camargo, 2009: The role of the Sahara low in summertime Sahel rainfall variability and change in the CMIP3 models. J. Climate, 22, 5755-5771, doi:10.1175/ 2009JCLI2969.1.

Chauvin, F., R. Roehrig, and J.-P. Lafore, 2010: Intraseasonal variability of the Saharan heat low and its link with midlatitudes. J. Climate, 23, 2544-2561, doi:10.1175/2010JCLI3093.1.

Chiang, J. C., and D. J. Vimont, 2004: Analogous Pacific and Atlantic meridional modes of tropical atmosphere-ocean variability in the tropical Pacific and tropical Atlantic. J. Climate, 17, 4143-4158, doi:10.1175/JCLI4953.1.

Cook, K. H., 1999: Generation of the African easterly jet and its role in determining West African precipitation. J. Climate, 12, 11651184, doi:10.1175/1520-0442(1999)012<1165:GOTAEJ > 2.0.CO;2.

_ , and E. K. Vizy, 2015: Detection and analysis of an amplified warming of the Sahara Desert. J. Climate, 28, 6560-6580, doi:10.1175/JCLI-D-14-00230.1.

Dee, D., and Coauthors, 2011: The ERA-Interim reanalysis: Configuration and performance of the data assimilation system. Quart. J. Roy. Meteor. Soc., 137, 553-597, doi:10.1002/qj.828.

Delcambre, S. C., D. J. Lorenz, D. J. Vimont, and J. E. Martin, 2013: Diagnosing Northern Hemisphere jet portrayal in 17 CMIP3 global climate models: Twentieth-century intermodel variability. J. Climate, 26, 4910-4929, doi:10.1175/ JCLI-D-12-00337.1.

Donner, L. J., and Coauthors, 2011: The dynamical core, physical parameterizations, and basic simulation characteristics of the atmospheric component AM3 of the GFDL global coupled model CM3. J. Climate, 24, 3484-3519, doi:10.1175/2011JCLI3955.1.

Drobinski, P., B. Sultan, and S. Janicot, 2005: Role of the Hoggar massif in the West African monsoon onset. Geophys. Res. Lett., 32, L01705, doi:10.1029/2004GL020710. 
Dufresne, J.-L., and Coauthors, 2013: Climate change projections using the IPSL-CM5 Earth system model: From CMIP3 to CMIP5. Climate Dyn., 40, 2123-2165, doi:10.1007/ s00382-012-1636-1.

Engelstaedter, S., R. Washington, C. Flamant, D. J. Parker, C. Allen, and M. Todd, 2015: The Saharan heat low and moisture transport pathways in the central Sahara-Multiaircraft observations and Africa-LAM evaluation. J. Geophys. Res. Atmos., 120, 4417-4442, doi:10.1002/2015JD023123.

Evan, A. T., C. Flamant, S. Fiedler, and O. Doherty, 2014: An analysis of aeolian dust in climate models. Geophys. Res. Lett., 41, 5996-6001, doi:10.1002/2014GL060545.

,,-- C. Lavaysse, C. Kocha, and A. Saci, 2015: Water vaporforced greenhouse warming over the Sahara Desert and the recent recovery from the Sahelian drought. J. Climate, 28, 108123, doi:10.1175/JCLI-D-14-00039.1.

Folland, C. K., T. N. Pamer, and D. E. Parker, 1986: Sahel rainfall and worldwide sea temperatures, 1901-85. Nature, 320, 602607, doi:10.1038/320602a0.

_ J. Knight, H. W. Linderholm, D. Fereday, S. Ineson, and J. W. Hurrell, 2009: The summer North Atlantic Oscillation: Past, present, and future. J. Climate, 22, 1082-1103, doi:10.1175/ 2008JCLI2459.1.

Frierson, D. M., and Coauthors, 2013: Contribution of ocean overturning circulation to tropical rainfall peak in the Northern Hemisphere. Nat. Geosci., 6, 940-944, doi:10.1038/ ngeo1987.

Fyfe, J. C., 1999: Climate simulations of African easterly waves. J. Climate, 12,1747-1769, doi:10.1175/1520-0442(1999)012<1747 CSOAEW $>2.0 . \mathrm{CO} ; 2$.

Gent, P. R., and Coauthors, 2011: The Community Climate System Model version 4. J. Climate, 24, 4973-4991, doi:10.1175/ 2011JCLI4083.1.

Giannini, A., R. Saravanan, and P. Chang, 2003: Oceanic forcing of Sahel rainfall on interannual to interdecadal time scales. Science, 302, 1027-1030, doi:10.1126/science.1089357.

—, S. Salack, T. Lodoun, A. Ali, A. Gaye, and O. Ndiaye, 2013: A unifying view of climate change in the Sahel linking intraseasonal, interannual and longer time scales. Environ. Res. Lett., 8, 024010, doi:10.1088/1748-9326/8/2/024010.

Haarsma, R. J., F. M. Selten, S. L. Weber, and M. Kliphuis, 2005: Sahel rainfall variability and response to greenhouse warming. Geophys. Res. Lett., 32, L17702, doi:10.1029/ 2005GL023232.

Hagos, S. M., and K. H. Cook, 2007: Dynamics of the West African monsoon jump. J. Climate, 20, 5264-5284, doi:10.1175/ 2007JCLI1533.1.

Held, I., T. Delworth, J. Lu, K. L. Findell, and T. Knutson, 2005: Simulation of Sahel drought in the 20th and 21st centuries. Proc. Natl. Acad. Sci. USA, 102, 17 891-17 896, doi:10.1073/ pnas.0509057102.

Hsieh, J.-S., and K. H. Cook, 2008: On the instability of the African easterly jet and the generation of African waves: Reversals of the potential vorticity gradient. J. Atmos. Sci., 65, 2130-2151, doi:10.1175/2007JAS2552.1.

Janiga, M. A., and C. D. Thorncroft, 2013: Regional differences in the kinematic and thermodynamic structure of African easterly waves. Quart. J. Roy. Meteor. Soc., 139, 1598-1614, doi:10.1002/ qj.2047.

Jeffrey, S., L. Rotstayn, M. Collier, S. Dravitzki, C. Hamalainen, C. Moeseneder, K. Wong, and J. Syktus, 2013: Australia's CMIP5 submission using the CSIRO Mk3.6 model. Aust. Meteor. Oceanogr. J., 63, 1-13.
Ji, D., and Coauthors, 2014: Description and basic evaluation of Beijing Normal University Earth System Model (BNU-ESM) version 1. Geosci. Model Dev., 7, 2039-2064, doi:10.5194/ gmd-7-2039-2014.

Jones, C., and Coauthors, 2011: The HadGEM2-ES implementation of CMIP5 centennial simulations. Geosci. Model Dev., 4, 543-570, doi:10.5194/gmd-4-543-2011.

Kang, S. M., L. Polvani, J. Fyfe, and M. Sigmond, 2011: Impact of polar ozone depletion on subtropical precipitation. Science, 332, 951-954, doi:10.1126/science.1202131.

Kim, D., A. H. Sobel, A. D. Del Genio, Y. Chen, S. J. Camargo, M.-S. Yao, M. Kelley, and L. Nazarenko, 2012: The tropical subseasonal variability simulated in the NASA GISS general circulation model. J. Climate, 25, 4641-4659, doi:10.1175/ JCLI-D-11-00447.1.

Kobayashi, S., and Coauthors, 2015: The JRA-55 reanalysis: General specifications and basic characteristics. J. Meteor. Soc. Japan, 93, 5-48, doi:10.2151/jmsj.2015-001.

Langenbrunner, B., J. D. Neelin, B. R. Lintner, and B. T. Anderson, 2015: Patterns of precipitation change and climatological uncertainty among CMIP5 models, with a focus on the midlatitude Pacific storm track. J. Climate, 28, 7857-7872, doi:10.1175/JCLI-D-14-00800.1.

Lavaysse, C., C. Flamant, S. Janicot, D. Parker, J.-P. Lafore, B. Sultan, and J. Pelon, 2009: Seasonal evolution of the West African heat low: a climatological perspective. Climate Dyn., 33, 313-330, doi:10.1007/s00382-009-0553-4.

, — , and - 2010a: Regional-scale convection patterns during strong and weak phases of the Saharan heat low. Atmos. Sci. Lett., 11, 255-264, doi:10.1002/asl.284.

,,,--- and P. Knippertz, 2010b: Links between African easterly waves, midlatitude circulation and intraseasonal pulsations of the West African heat low. Quart. J. Roy. Meteor. Soc., 136, 141-158, doi:10.1002/qj.555.

J.-P. Chaboureau, and C. Flamant, 2011: Dust impact on the West African heat low in summertime. Quart. J. Roy. Meteor. Soc., 137, 1227-1240, doi:10.1002/qj.844.

, C. Flamant, A. Evan, S. Janicot, and M. Gaetani, 2015: Recent climatological trend of the Saharan Heat Low and its impact on the West African climate. Climate Dyn., 47, 34793498, doi:10.1007/s00382-015-2847-z.

Li, L., and Coauthors, 2013: The flexible global ocean-atmosphereland system model, grid-point version 2: FGOALS-g2. $A d v$. Atmos. Sci., 30, 543-560, doi:10.1007/s00376-012-2140-6.

Liu, Y., J. C. Chiang, C. Chou, and C. M. Patricola, 2014: Atmospheric teleconnection mechanisms of extratropical North Atlantic SST influence on Sahel rainfall. Climate Dyn., 43, 2797-2811, doi:10.1007/s00382-014-2094-8.

Lorenz, C., and H. Kunstmann, 2012: The hydrological cycle in three state-of-the-art reanalyses: Intercomparison and performance analysis. J. Hydrometeor., 13, 1397-1420, doi:10.1175/ JHM-D-11-088.1.

Monerie, P.-A., B. Fontaine, and P. Roucou, 2012: Expected future changes in the African monsoon between 2030 and 2070 using some CMIP3 and CMIP5 models under a medium-low RCP scenario. J. Geophys. Res., 117, D16111, doi:10.1029/ 2012JD017510.

, P. Roucou, and B. Fontaine, 2013: Mid-century effects of climate change on African monsoon dynamics using the A1B emission scenario. Int. J. Climatol., 33, 881-896, doi:10.1002/ joc.3476.

Ndiaye, O., M. N. Ward, and W. M. Thiaw, 2011: Predictability of seasonal Sahel rainfall using GCMs and lead-time improvements 
through the use of a coupled model. J. Climate, 24, 1931-1949, doi:10.1175/2010JCLI3557.1.

Neale, R. B., and Coauthors, 2012: Description of the NCAR Community Atmosphere Model (CAM 5.0). NCAR Tech. Rep. NCAR/TN-486+STR, 268 pp. [Available online at http:// www.cesm.ucar.edu/models/cesm1.0/cam/docs/description/ cam5_desc.pdf.]

Nicholson, S. E., 2013: The West African Sahel: A review of recent studies on the rainfall regime and its interannual variability. Int. Scholarly Res. Not. Meteor., 2013, 453521, doi:10.1155/ 2013/453521.

Park, J.-Y., J. Bader, and D. Matei, 2015: Northern-Hemispheric differential warming is the key to understanding the discrepancies in the projected Sahel rainfall. Nat. Commun., 6, 5985, doi:10.1038/ncomms6985.

Previdi, M., and B. G. Liepert, 2007: Annular modes and Hadley cell expansion under global warming. Geophys. Res. Lett., 34, L22701, doi:10.1029/2007GL031243.

Ramel, R., H. Gallée, and C. Messager, 2006: On the northward shift of the West African monsoon. Climate Dyn., 26, 429-440, doi:10.1007/s00382-005-0093-5.

Rienecker, M. M., and Coauthors, 2011: MERRA: NASA's ModernEra Retrospective Analysis for Research and Applications. J. Climate, 24, 3624-3648, doi:10.1175/JCLI-D-11-00015.1.

Roberts, A. J., J. H. Marsham, and P. Knippertz, 2015: Disagreements in low-level moisture between (re)analyses over summertime West Africa. Mon. Wea. Rev., 143, 1193-1211, doi:10.1175/MWR-D-14-00218.1.

Rodríguez-Fonseca, B., and Coauthors, 2015: Variability and predictability of West African droughts: A review on the role of sea surface temperature anomalies. J. Climate, 28, 4034-4060, doi:10.1175/JCLI-D-14-00130.1.

Rodwell, M. J., and B. J. Hoskins, 1996: Monsoons and the dynamics of deserts. Quart. J. Roy. Meteor. Soc., 122, 1385-1404, doi:10.1002/qj.49712253408.

Roehrig, R., F. Chauvin, and J.-P. Lafore, 2011: 10-25-day intraseasonal variability of convection over the Sahel: A role of the Saharan heat low and midlatitudes. J. Climate, 24, 5863-5878, doi:10.1175/2011JCLI3960.1.

—, D. Bouniol, F. Guichard, F. Hourdin, and J.-L. Redelsperger, 2013: The present and future of the West African monsoon: A process-oriented assessment of CMIP5 simulations along the AMMA transect. J. Climate, 26, 64716505, doi:10.1175/JCLI-D-12-00505.1.

Saha, S., and Coauthors, 2010: The NCEP Climate Forecast System Reanalysis. Bull. Amer. Meteor. Soc., 91, 1015-1057, doi:10.1175/ 2010BAMS3001.1.

Schneider, T., T. Bischoff, and G. H. Haug, 2014: Migrations and dynamics of the intertropical convergence zone. Nature, 513, 45-53, doi:10.1038/nature13636.
Scoccimarro, E., and Coauthors, 2011: Effects of tropical cyclones on ocean heat transport in a high-resolution coupled general circulation model. J. Climate, 24, 4368-4384, doi:10.1175/ 2011JCLI4104.1.

Stevens, B., and Coauthors, 2013: Atmospheric component of the MPI-M Earth system model: ECHAM6. J. Adv. Model. Earth Syst., 5, 146-172, doi:10.1002/jame.20015.

Sultan, B., and S. Janicot, 2003: The West African monsoon dynamics. Part II: The preonset and onset of the summer monsoon. J. Climate, 16, 3407-3427, doi:10.1175/1520-0442(2003)016<3407: TWAMDP $>2.0 . \mathrm{CO} ; 2$.

— - _ and A. Diedhiou, 2003: The West African monsoon dynamics. Part I: Documentation of intraseasonal variability. J. Climate, 16, 3389-3406, doi:10.1175/1520-0442(2003)016<3389: TWAMDP $>2.0 . \mathrm{CO} ; 2$

Taylor, K. E., R. J. Stouffer, and G. A. Meehl, 2012: An overview of CMIP5 and the experiment design. Bull. Amer. Meteor. Soc., 93, 485-498, doi:10.1175/BAMS-D-11-00094.1.

Thorncroft, C., and M. Blackburn, 1999: Maintenance of the African easterly jet. Quart. J. Roy. Meteor. Soc., 125, 763-786.

Vellinga, M., A. Arribas, and R. Graham, 2013: Seasonal forecasts for regional onset of the West African monsoon. Climate Dyn., 40, 3047-3070, doi:10.1007/s00382-012-1520-z.

Vizy, E. K., and K. H. Cook, 2009: A mechanism for African monsoon breaks: Mediterranean cold air surges. J. Geophys. Res., 114, D01104, doi:10.1029/2008JD010654.

- - —, J. Crtat, and N. Neupane, 2013: Projections of a wetter Sahel in the twenty-first century from global and regional models. J. Climate, 26, 4664-4687, doi:10.1175/ JCLI-D-12-00533.1.

Voldoire, A., and Coauthors, 2013: The CNRM-CM5.1 global climate model: Description and basic evaluation. Climate Dyn., 40, 2091-2121, doi:10.1007/s00382-011-1259-y.

Volodin, E., N. Dianskii, and A. Gusev, 2010: Simulating presentday climate with the INMCM4.0 coupled model of the atmospheric and oceanic general circulations. Izv., Atmos. Oceanic Phys., 46, 414-431, doi:10.1134/S000143381004002X.

Watanabe, M., and Coauthors, 2010: Improved climate simulation by MIROC5: Mean states, variability, and climate sensitivity. J. Climate, 23, 6312-6335, doi:10.1175/2010JCLI3679.1.

Wu, T., and Coauthors, 2014: An overview of BCC climate system model development and application for climate change studies. J. Meteor. Res., 28, 34-56, doi:10.1007/s13351-014-3041-7.

Xie, S.-P., and S. G. H. Philander, 1994: A coupled ocean-atmosphere model of relevance to the ITCZ in the eastern Pacific. Tellus, 46A, 340-350, doi:10.1034/j.1600-0870.1994.t01-1-00001.x.

Yukimoto, S., and Coauthors, 2012: A new global climate model of the Meteorological Research Institute: MRI-CGCM3 model description and basic performance.J. Meteor. Soc. Japan, $\mathbf{9 0 A}$, 23-64, doi:10.2151/jmsj.2012-A02. 